\title{
Electromagnetic Wave Absorption of Periodic Cylindrical Structured Gypsum Composites Incorporate With Different Carbonaceous Materials
}

\section{Shuai Xie( $\sim$ xs5649@163.com )}

China Building Materials Academy https://orcid.org/0000-0001-6774-5224

\section{Yuan Zhang}

China Building Materials Academy

\section{Zhijiang Ji}

China Building Materials Academy

\section{Jing Wang}

China Building Materials Academy

\section{Research Article}

Keywords: Wave absorption, 3D Periodic structure, Gypsum composite, Carbonaceous materials, Broadband

Posted Date: February 22nd, 2021

DOl: https://doi.org/10.21203/rs.3.rs-162584/v1

License: (9) This work is licensed under a Creative Commons Attribution 4.0 International License. Read Full License

Version of Record: A version of this preprint was published at Journal of Materials Science: Materials in Electronics on March 12th, 2021. See the published version at https://doi.org/10.1007/s10854-02105586-2. 
Electromagnetic wave absorption of periodic cylindrical structured gypsum composites incorporate with different carbonaceous materials

\author{
Shuai Xie ${ }^{1,2^{*}}$, Yuan Zhang ${ }^{1,2}$, Zhijiang $\mathrm{Ji}^{1,2}$, Jing Wang ${ }^{1,2}$ \\ ${ }^{1}$ China Building Materials Academy, Beijing 100024, P. R. China \\ ${ }^{2}$ State Key Laboratory of Green Building Materials, Beijing 100024, P. R. China
}

*Corresponding author: Shuai Xie; Email: xs5649@163.com 


\begin{abstract}
In order to improve the impedance matching condition and broaden the effective absorbing bandwidth, a series of cylindrical periodic structured gypsum composites with different kinds of carbonaceous materials as absorbents were fabricated by two-step moulding process. The influences of the mass fraction of helical carbon fiber (HCF), carbon nanotube (CNT), and graphene (GE) on the morphology, permittivity, resistivity, and electromagnetic (EM) wave absorbing properties of the proposed gypsum composites were investigated. The experimental results show that the composite with 2 wt.\% HCF exhibits optimum EM wave absorption performance, its reflection loss is lower than $-10 \mathrm{~dB}$ in 2-18 GHz and bandwidth thickness ratio coefficient reaches $0.8 \mathrm{GHz} / \mathrm{mm}$. The EM wave absorption mechanisms were further explained by the simulation of EM field and power loss distribution. The dielectric loss of carbonaceous absorbents, the destructive interference, and the EM wave diffraction and multiple refractions caused by the periodic cylindrical arrays are the main EM wave attenuation mechanisms of the fabricated composites. This study could provide guidance for the design of broadband EM wave absorbing materials.
\end{abstract}

Keywords: Wave absorption; 3D Periodic structure; Gypsum composite; Carbonaceous materials; Broadband 


\section{Introduction}

Electromagnetic (EM) interference, health hazard and information leakage caused by EM radiation have become serious issues in modern society [1,2]. To solve these problems, it is essential to use EM wave absorbing building materials in civil engineer, endowing buildings with EM radiation protection function. Thus, many researchers have attempted to develop EM wave absorbing building materials, and more and more building materials with EM wave absorption ability, such as cement materials [3-6], ceramic materials [7,8], and other composites [9-11], have been reported in recent years. Most of the EM wave absorbing building materials are fabricated by merely introducing dielectric or magnetic absorbents. However, owing to impedance mismatching caused by the unilateral increase of permittivity or permeability, these materials only can exhibit ideal EM absorbing performance in some specific frequency bands, and broadband EM absorption cannot be obtained. In addition, some metallic materials with high density will limit the application of building materials due to the dramatic increase of the weight, so lightweight carbonaceous materials are the best absorbents for developing EM wave absorbing building materials.

Structural design is a feasible way to enhance the EM absorption capability and broaden the effective bandwidth. The multilayer structure is one of the most common structures in the fabrication of EM wave absorbing building materials [12-15]. Sun et al. [13] designed a 3D extruded and sprayed graded double-layer EM wave absorbing cement materials, the specimen comprises a $15 \mathrm{~mm}$ impedance matching layer and a 15 $\mathrm{mm}$ absorbing layer shows optimum EM absorption performance, and an effective bandwidth of $9.56 \mathrm{GHz}$ can be attained. The porous aggregates, such as expanded perlite [16-18], glass beads [19,20], etc., are often used to adjust the pore structures of building materials, improving EM wave absorption properties. Wang et al. [16] uses the expanded perlite to optimize the impedance matching of the cement matrix, when the cement composites contains $10 \mathrm{wt} . \%$ expanded perlite and $40 \mathrm{wt} . \%$ fly ash, the maximum absorption bandwidth with reflection loss (RL) of $-10 \mathrm{~dB}$ reaches approximately $14 \mathrm{GHz}$ in the $2-18 \mathrm{GHz}$ ranges. The effective 
bandwidth for $-10 \mathrm{~dB}$ of the gypsum composite filled with $3 \mathrm{wt} \% \%$ carbon black (CB) and 40 vol.\% expanded perlites can be broader than $12.5 \mathrm{GHz}$ [17]. However, the thickness of these multilayer and porous structured materials is nearly $30 \mathrm{~mm}$, the bandwidth thickness ratio is low.

Design of planar periodic structure can achieve the thin thickness development of EM wave absorbers, but effective absorption can be obtained only in their resonance frequency bands. In order to broaden the bandwidth of periodic structured absorbers, multiple resonance structure [21-23] and three-dimensional (3D) structure [24-30] were designed. However, complex manufacturing processes of multiple resonance structured absorber confine their further applications. Nowadays, researchers have paid more and more attentions on 3D periodic structures, which can greatly enhance the EM attenuation capacity and broaden effective bandwidth by the synergistic action of microscopic and macroscopic effects [28]. A two-layer periodic stepped structured absorber engraved through a numerically controlled lathe exhibits broadband EM wave absorbing performance, and its RL can be less than $-10 \mathrm{~dB}$ in 2.64-40 GHz [29]. Fan et al. [30] fabricated a broadband absorbing composites with 3D periodic structure via hot-press moulding, its absorbing bandwidth of $\mathrm{RL}<$ $-10 \mathrm{~dB}$ can span from $2 \mathrm{GHz}$ to $30 \mathrm{GHz}$. But the above process is not applicable to the building material matrix. In our previous study, a cylindrical periodic structured gypsum absorber with CB as absorbent was fabricated by a two-step molding process, and the RL of the fabricated absorber is lower than $-10 \mathrm{~dB}$ in $2-18 \mathrm{GHz}$ [31]. However, the effects of different kinds of absorbents and EM absorption mechanisms need to be further investigated.

In this study, cylindrical periodic structured gypsum composites incorporate with different carbonaceous materials, such as graphene (GE), carbon nanotube (CNT) and helical carbon fiber (HCF), were fabricated, and the effects of carbonaceous materials mass fraction on the EM parameters, conductivity and EM absorption performance of the gypsum composites were studied. In addition, the EM absorption mechanisms were discussed combined with EM field and power loss simulation. This paper could provide some guiding 
suggestions for the design of wideband EM wave absorbing building materials.

\section{Experimental}

\subsection{Materials}

The gypsum powder, produced by Meilijia building materials (Beijing) co., Ltd, China, was used as matrix materials. Its initial and final setting time is $10 \mathrm{~min}$ and $25 \mathrm{~min}$, respectively, and its chemical components are shown in Table 1. Helical carbon fiber (HCF) was supplied by Guangdong Shuanghong New Material Technology Co., Ltd., China. Carbon nanotube (CNT) and Graphene (GE) were produced by Shenzhen Hongdachang Evolution Technology Co., Ltd., China. The basal properties of HCF, CNT and GE are listed in Table 2. Acrylonitrile butadiene styrene (ABS) plastic, supplied by Hangzhou Zhuopu New Material Technology Co. Ltd., China, was selected as the matrix materials to prepare the master mould by 3D printing. Silicone rubber (SLR) and vulcanizing agent were used to fabricate flexible mould, which were produced by Guangdong Huachuang Chemical Co. Ltd., China. Additionally, the carbon materials dispersant and deionized water were needed as well.

Table 1 Chemical composition of gypsum

\begin{tabular}{ccccccccc}
\hline Component & $\mathrm{CaSO}_{4}$ & $\mathrm{MgO}$ & $\mathrm{SiO}_{2}$ & $\mathrm{SrO}$ & $\mathrm{Al}_{2} \mathrm{O}_{3}$ & $\mathrm{Fe}_{2} \mathrm{O}_{3}$ & $\mathrm{~K}_{2} \mathrm{O}$ & $\mathrm{BaO}$ \\
\hline Content (wt.\%) & 92.593 & 4.038 & 2.359 & 0.360 & 0.310 & 0.144 & 0.054 & 0.003 \\
\hline \multicolumn{5}{c}{ Table 2 Basal properties of carbonaceous materials } \\
\hline Carbonaceous materials & Helical carbon fiber & Carbon nanotube & Graphene \\
\hline Bulk density (g/cm $\left.{ }^{3}\right)$ & 0.12 & 0.06 & 0.20 \\
\hline Specific surface area (m²/g) & 500 & 270 & 150 \\
\hline Conductivity (S/cm) & $>220$ & $>150$ & $>100$ \\
\hline
\end{tabular}




\subsection{Sample fabrication}

\subsubsection{Sample fabrication for RL measurement}

Samples for RL measurement were fabricated by two-step methods, as shown in Fig. 1. The specific procedures of sample fabrication are as follow:

(1) Preparation of flexible mould: An ABS master mould with a size of $180 \mathrm{~mm} \times 180 \mathrm{~mm}$ was printed by a 3D printer. The printed ABS mould was put in a same size steel container, and then the pre-weighed SLR mixed with vulcanizing agent was poured into the container. After vibrated and solidified, the flexible mould was obtained. The SLR/vulcanizing agent ratio by weight was selected as 1:0.05.

(2) Fabrication of gypsum absorber with cylindrical periodic arrays: Carbon materials and dispersant were first mixed in pre-weighted deionized water, and ultrasonic dispersed for approximately 20 minutes. Then adding the pre-weighted gypsum powder into the solution, and mixed for 2 minutes to obtain the gypsum slurry. The carbon materials/dispersant and gypsum/deionized water mass ratios were selected as 1:0.2 and 1:0.5, respectively. The prepared SLR flexible mould was put in an oiled steel enclosure, and poured the gypsum slurry into the steel enclosure and vibrated. The sample was removed after $2 \mathrm{~h}$ and dried in a thermostatic drier box with the temperature of $50{ }^{\circ} \mathrm{C}$ until its quality was constant.

The carbon absorbent mass fraction of the samples is $0.5 \%, 1 \%, 1.5 \%$ and $2 \%$. The geometrical parameters of the cylindrical periodic arrays are selected according to our previous study [31], the diameter and height of cylindrical periodic arrays are $20 \mathrm{~mm}$ and $15 \mathrm{~mm}$, respectively.
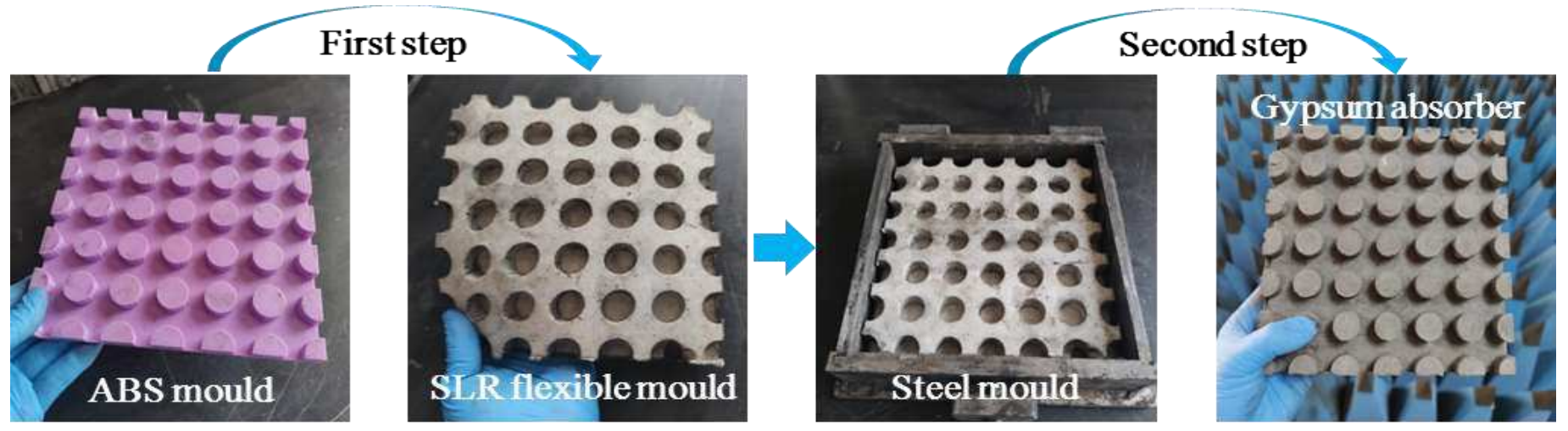
Fig. 1. The procedures of cylindrical periodic structured gypsum absorber fabrication.

\subsubsection{Sample fabrication for permittivity test}

The sample for the permittivity test by waveguide method was fabricated using a special mould. The samples are rectangle, and the sizes are $10.2 \mathrm{~mm} \times 22.9 \mathrm{~mm} \times 10 \mathrm{~mm}$ (for X-band) and $7.9 \mathrm{~mm} \times 15.8 \mathrm{~mm} \times$ $10 \mathrm{~mm}$ (for Ku-band), respectively. The fabrication procedure of the toroidal shape samples for permittivity measurement by coaxial method is as below: the tested materials were dispersed in molten paraffin wax, and molded into toroidal shaped samples with $7 \mathrm{~mm}$ inner diameter, $3.04 \mathrm{~mm}$ external diameter and $3 \sim 5 \mathrm{~mm}$ thickness. The volume fraction of the tested materials in the samples was 50 vol.\%. The photographs of the samples for waveguide method and coaxial method are illustrated in Fig. 2.

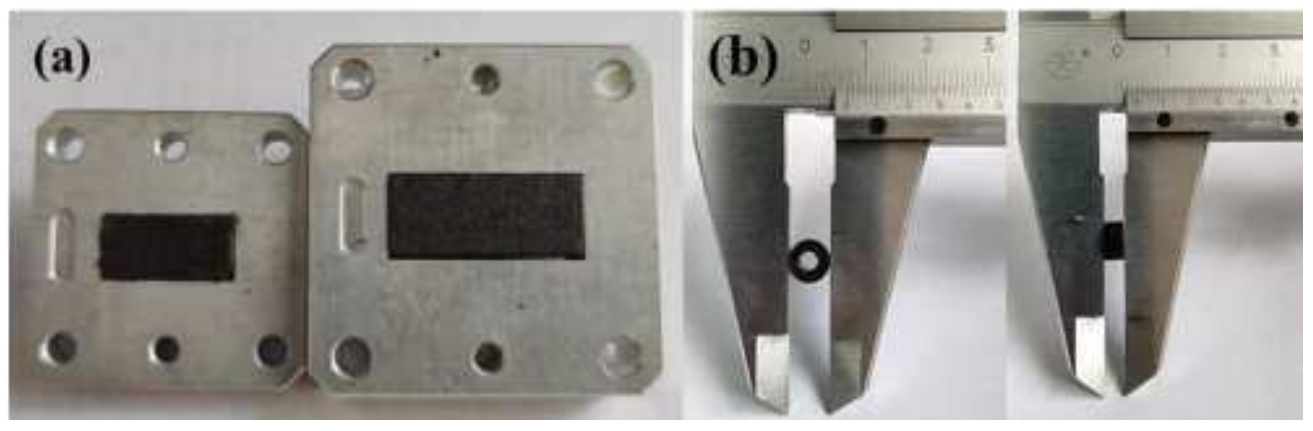

Fig. 2. Photograph of the samples for waveguide method (a) and coaxial method (b).

\subsection{Characterization}

The morphology and microstructure of HCF, CNT, GE and gypsum composites were investigated by means of scanning electron microscopy (SEM, Quanta200). The electric resistance of gypsum composites was measured by a digital multimeter, and the corresponding resistivity $(\rho)$ was calculated by $\rho=R S / L$, where, $S$ is the cross-sectional area of the sample, $L$ is the length of the sample, $R$ is the electric resistance of the sample. The sample size parameters were selected as $10 \mathrm{~mm} \times 10 \mathrm{~mm} \times 50 \mathrm{~mm}$. The flexural strength of the gypsum composites incorporate with different carbonaceous materials was tested by a Testing Antifracture Machine (TYE-6A), and the loading rate selected as $0.05 \mathrm{kN} / \mathrm{S}$. The sample size was $40 \mathrm{~mm} \times 40 \mathrm{~mm} \times 160 \mathrm{~mm}$. 
The permittivity of raw materials was measured by coaxial method in the frequency range of $2 \sim 18 \mathrm{GHz}$, and the permittivity of the prepared gypsum composites with different carbon absorbents was measured by waveguide method in 8.2 18 GHz. The EM wave absorption properties were tested by the arch test method in 2 18 GHz. An Agilent N5234A Vector Network Analyzer, $140 \mathrm{~mm}$ coaxial airline, X-band and Ku-band waveguide, six pairs of horn antennas, and Agilent $85071 \mathrm{E}$ measurement software were used. The testing system of coaxial method, waveguide method and arch method are presented in Fig. 3 (a), (b) and (c), respectively. High Frequency Structure Simulator (HFSS) software was used to simulate the EM field distribution in $8.2 \sim 18 \mathrm{GHz}$.

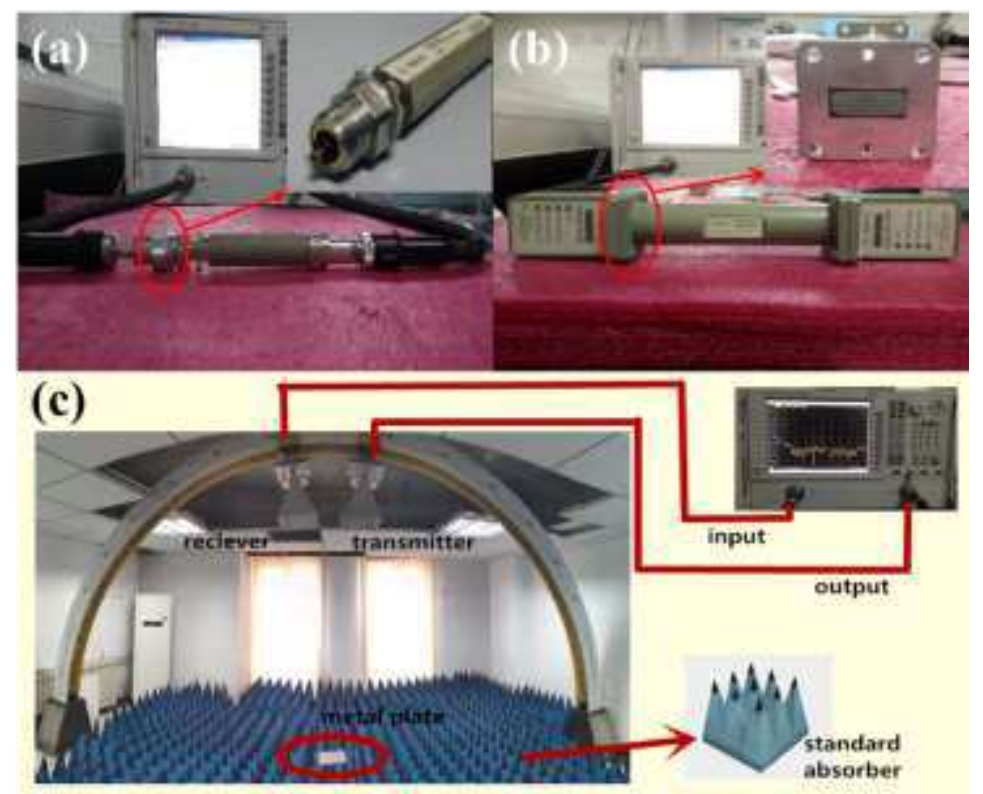

Fig. 3. Testing system of coaxial method (a), waveguide method (b) and arch method system (d).

\section{Results and discussion}

\subsection{Microstructures and electromagnetic properties of different carbonaceous materials}

The microstructures of the used carbon materials were evaluated by SEM measurement, as illustrated in Fig. 4. The morphology of HCFs is shown in Fig. 4 (a), it can be observed that the HCFs have a typical spiral chiral morphology without coil gap. The coil length of HCFs is in a wide range from about $5 \mu \mathrm{m}$ to $100 \mu \mathrm{m}$, 
and its external coil diameter is approximately less than $10 \mu \mathrm{m}$. Fig. 4 (b) presented the configuration of CNT, from which it can be seen that the CNT curved to be entangled and cross-linked together, and its external diameter is nanometer scale. The microtopography of GE sheets was illustrated in Fig. 4 (c), and it can be seen that the GE sheets curl slightly, and show an irregular shape. The measurements of the GE sheets are in the range of 50 500 $\mu \mathrm{m}$ approximately.

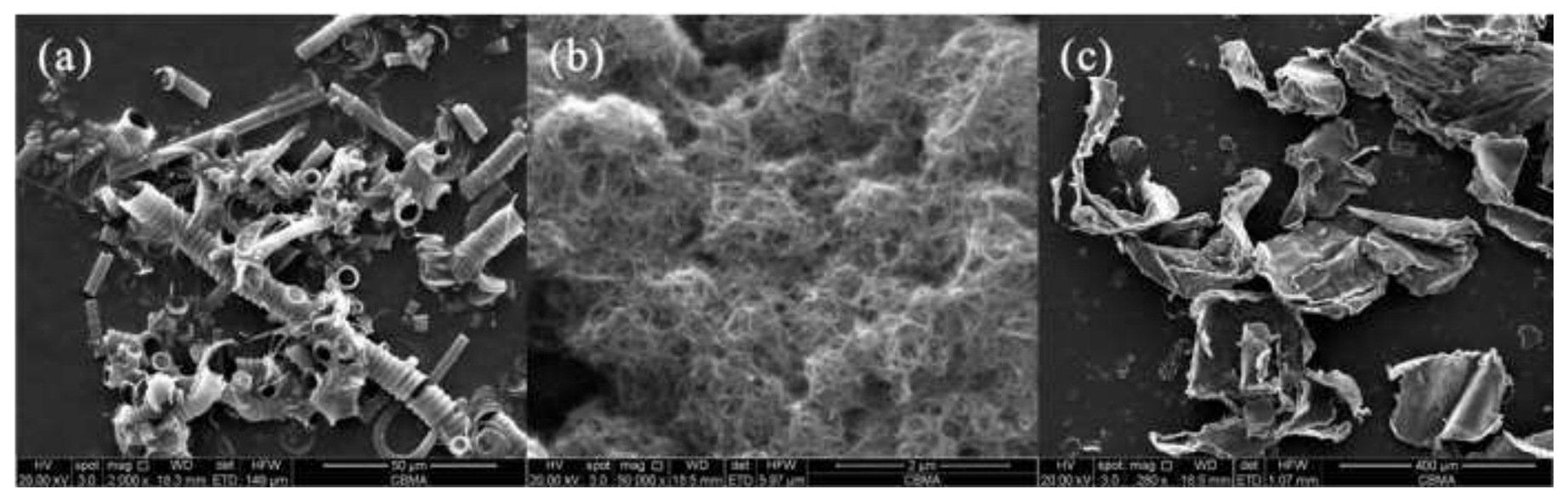

Fig. 4. SEM images of HCF (a), CNT (b) and GE (c).

As the carbon materials possess no magnetic properties, only the dielectric properties of three kinds of carbon materials was investigated via coaxial method in 2-18 GHz. Dielectric properties of the dielectric materials are characterized by complex permittivity $\varepsilon$, which can be expressed as $\varepsilon=\varepsilon^{\prime}-j \varepsilon^{\prime \prime}$. The terms $\varepsilon^{\prime}$ is associated with energy storage, and $\varepsilon^{\prime \prime}$ stands for the energy dissipation from conduction, dipolar, relaxation and any other mechanisms. The EM attenuation capacity of dielectric materials can be substituted by the dielectric loss factor, which can be calculated by $\tan \delta_{e}=\varepsilon^{\prime \prime} / \varepsilon^{\prime}[32]$.

The permittivity and dielectric loss factor of the used carbon materials in this study are presented in Fig.5. Fig. 5 (a) shows the permittivity of $\mathrm{HCF}$, from which it can be observed that the real part $\left(\varepsilon^{\prime}\right)$ of complex permittivity decreases from 24.4 to 8.7 , and the imaginary part $\left(\varepsilon^{\prime \prime}\right)$ declines from 22.1 to 7.3 , with the frequency increase. The $\varepsilon^{\prime}$ and $\varepsilon^{\prime \prime}$ of CNT exhibit similar trend, the $\varepsilon^{\prime}$ declines from 16.5 to 10.4 , meanwhile the $\varepsilon^{\prime \prime}$ declines from 10.7 to 4.4, as shown in Fig. 5 (b). The $\varepsilon^{\prime}$ of GE slightly fluctuates in the range of 6.6-8.1, and the $\varepsilon^{\prime \prime}$ increases from 1.8 to 3.8 with the increase of frequency, which can be found in Fig. 5(c). The 
dielectric loss factors $\left(\tan \delta_{e}\right)$ of the three kinds of carbon materials are illustrated in Fig. 5 (d), and it is visibly that the order of the loss factor is $\mathrm{HCF}>\mathrm{CNT}>\mathrm{GE}$. The $\tan \delta_{e}$ of $\mathrm{HCF}$ increases first and then decreases, and its maximum value of 1.23 is obtained in $10.5 \mathrm{GHz}$. The $\tan \delta_{e}$ of CNT and GE are in the range of $0.33-0.68$ and $0.2-0.54$, respectively. The above results indicates that the HCF possess higher EM attenuation ability than CNT and GE.
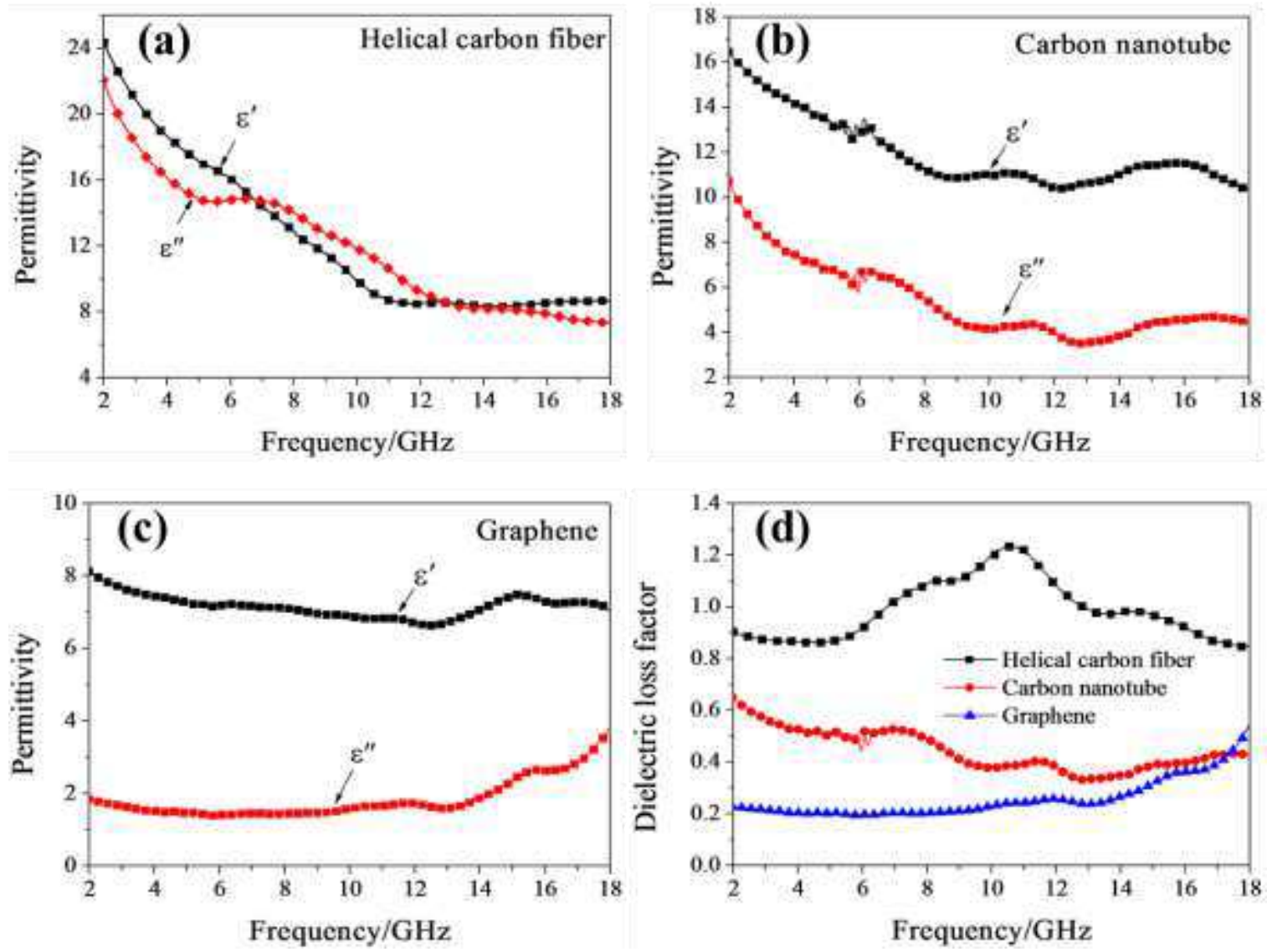

Fig. 5. Permittivity and dielectric loss factor of different carbon materials: (a) Permittivity of HCF; (b) Permittivity of CNT;

(c) Permittivity of GE; (d) Dielectric loss factor of three kinds of carbon materials.

\subsection{Microstructures of gypsum composites with different carbon absorbents}

The microstructures of the fractured cross section of the specimens with different carbonaceous materials were observed by SEM, as illustrated in Fig. 6. It is obvious that more and more carbonaceous materials appear in the field of view with the increase of mass fraction, and the morphology of gypsum hydration products cannot be significantly affected by adding different carbonaceous materials. 


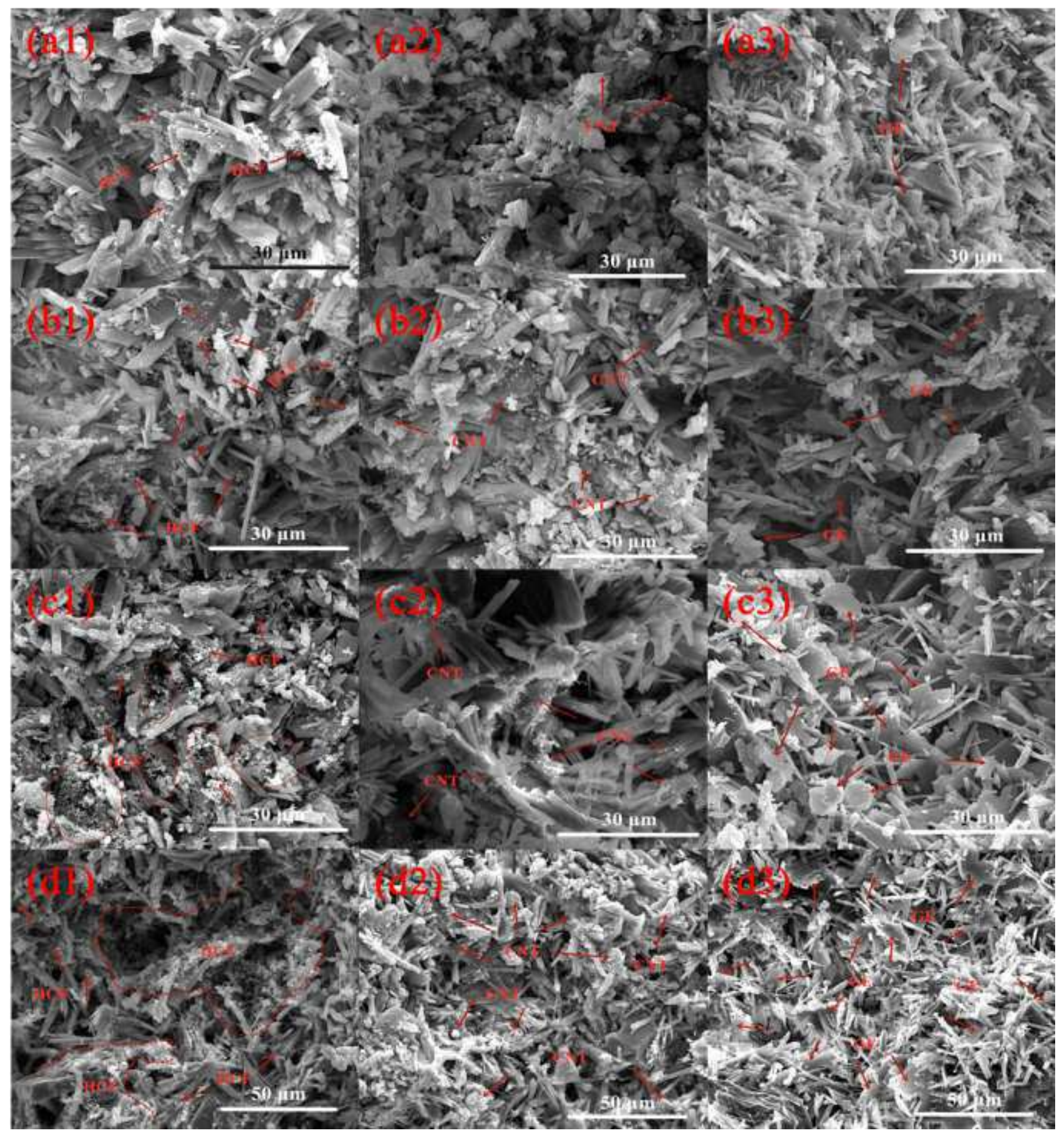

Fig. 6. SEM images of gypsum composites with different carbon materials: (a1)-(d1) composites with 0.5 wt.\%, 1 wt.\%, 1.5 wt.\%, and 2 wt.\% HCF; (a2)-(d2) composites with 0.5 wt.\%, 1 wt.\%, 1.5 wt.\%, and 2 wt.\% CNT; (a3)-(d3) composites with 0.5 wt. $\%, 1$ wt. $\%, 1.5$ wt. $\%$, and 2 wt. $\%$ GE.

The dispersion states of HCFs in gypsum matrix can be obtained in Fig. 6 (a1-d1). It is found that the small agglomerated particles of HCFs are distributed independently in the matrix when its mass fraction is 
lower than $1 \%$. As the HCF mass fraction increases to $1.5 \%$, the HCF aggregates become much bigger distinctly. However, most aggregates still remain independent. It is visibly that the adjacent HCFs aggregates are connected to each other when the HCF mass fraction is $2 \%$, forming local conductive network in gypsum matrix, which is beneficial to the enhancement of conductivity.

Fig. $6(a 2-d 2)$ show the morphology of the specimens with different mass fraction of CNTs. For the gypsum matrix with $0.5 \% \mathrm{CNT}$, the CNT cannot be easily observed. And CNT clumps with the diameters of nearly exceeding $10 \mu \mathrm{m}$ can be frequently found when the specimen with $1 \%$ or $1.5 \%$ CNT. When the CNT mass fraction increases to $2 \%$, the diameter of CNT clusters constantly grows, and most of the clusters are entwined with each other. It is also found that the HCF and CNT are trending to be agglomerated at the intersections of the hydrated gypsum fibers.

The SEM images of the cross sections of gypsum composites with different GE mass fractions are shown in Fig. (a3-d3). Compared with HCF and CNT, the GE sheets were prone to be embedded in the gypsum hydration products, thus, GE sheets are independently dispersed in gypsum matrix when the GE mass fraction is less than $1.5 \%$. When the gypsum matrix contains $2 \%$ GE, GE sheets are slightly stacked in disorder, and the distance between adjacent GE sheets is shortened and even contact with each other.

\subsection{Permittivity and resistivity of gypsum composites with different carbon absorbents}

The permittivity of gypsum composites with different carbon absorbents was investigated by wave-guide method in 8.2-18 GHz, and the results are shown in Fig. 7. Their permittivity in 2-8.2 GHz cannot be measured because of the limitation of wave-guide method condition.

Fig. 7 (a)-(c) show the $\varepsilon^{\prime}, \varepsilon^{\prime \prime}$ and $\tan \delta_{e}$ of gypsum composites with different mass fractions of HCF. It can be seen that the $\varepsilon^{\prime}, \varepsilon^{\prime \prime}$ and $\tan \delta_{e}$ all increase with the increase of HCF mass fraction. When the composite with $2 \% \mathrm{HCF}$, its $\varepsilon^{\prime}, \varepsilon^{\prime \prime}$ and $\tan \delta_{e}$ can be in the ranges of 5.42-5.88, 2.15-3.03 and 0.38-0.52, respectively, which possesses high dielectric loss capacity. The variations of $\varepsilon^{\prime}, \varepsilon^{\prime \prime}$ and $\tan \delta_{e}$ of the CNT/gypsum composites 
exhibits the similar regularity, as shown in Fig. 7 (d)-(f). The $\varepsilon^{\prime}$ and $\varepsilon^{\prime \prime}$ of the composites with $2 \%$ CNT fluctuate in the ranges of 4.60-5.05 and 0.85-1.09, respectively, and its $\tan \delta_{e}$ fluctuates between 0.17 and 0.23 . The permittivity and loss factor of the composites with different mass fractions of GE are illustrated in Fig. 7 (g)(i), the $\varepsilon^{\prime}, \varepsilon^{\prime \prime}$ and $\tan \delta_{e}$ increase with the enhancement of GE mass fraction. When GE mass fraction is $2 \%$, the $\varepsilon^{\prime}$ increases from 4.82 to 5.63 with increase of frequency, and the $\varepsilon^{\prime \prime}$ and $\tan \delta_{e}$ fluctuate drastically in the ranges 0.03-0.58 and 0.01-0.11, respectively. It also can be found from Fig. 7 that the $\varepsilon^{\prime}, \varepsilon^{\prime \prime}$ and $\tan \delta_{e}$ of the composites with HCF are higher than those with CNT or GE under the same mass fraction. And the order of the enhancement to the permittivity and loss factor of gypsum matrix is $\mathrm{HCF}>\mathrm{CNT}>\mathrm{GE}$, which is closely related to their intrinsic dielectric characteristics.
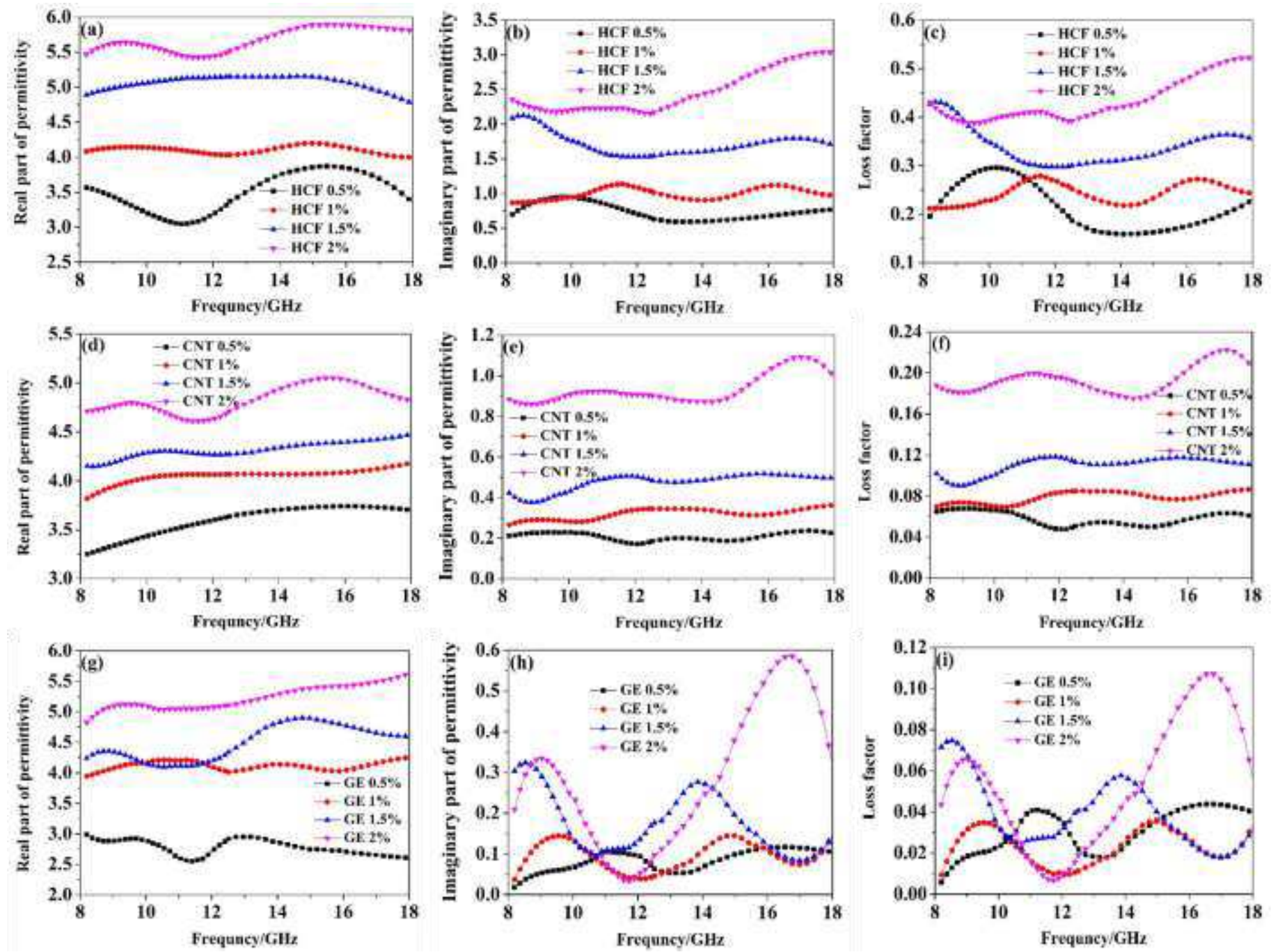

Fig. 7. Permittivity and loss factor of gypsum based composites with different carbon materials: (a) (c) $\varepsilon^{\prime}, \varepsilon^{\prime \prime}$ and loss factor 
of $\mathrm{HCF} /$ gypsum composites; (d) (f) $\varepsilon^{\prime}, \varepsilon^{\prime \prime}$ and loss factor of CNT/gypsum composites; (g) (i) $\varepsilon^{\prime}, \varepsilon^{\prime \prime}$ and loss factor of GE/gypsum composites.

When the carbon absorbents disperse in gypsum matrix, the conductivity of gypsum matrix will be changed by the gradual formation of conductive network. In order to investigate the effects of carbon absorbents mass fraction on the conductivity of gypsum composites, the resistivity $(\rho)$ of the gypsum composites with different carbon absorbents were measured, and the results are shown in Fig. 8. It is visible that the resistivity of the composite with GE is the highest and that with HCF is the lowest under same mass fractions. And the resistivity of gypsum composites monotonically decreasing with the increase of carbon absorbents mass fraction, which is consistent with the variation rule of dielectric constant.

For a typical dielectric material, the relaxation loss originated from polarization effects and conductance loss due to the moving of charge carriers under applied EM field will lead to the increase of $\varepsilon^{\prime \prime}$. The $\varepsilon^{\prime \prime}$ can be determined by $\varepsilon^{\prime \prime}=\sigma / 2 \pi f \varepsilon_{0}[33,34]$, where $\sigma$ is the conductivity, $f$ is the frequency and $\varepsilon_{0}$ is the free space permittivity. It reveals that the $\varepsilon^{\prime \prime}$ of a dielectric material is positively correlated with $\sigma$, that is negatively correlated with $\rho$. Therefore, for the composites with different carbon absorbents, the variation of $\varepsilon^{\prime \prime}$ and conductivity exhibits similar regularity with the variation of carbon absorbents mass fraction.

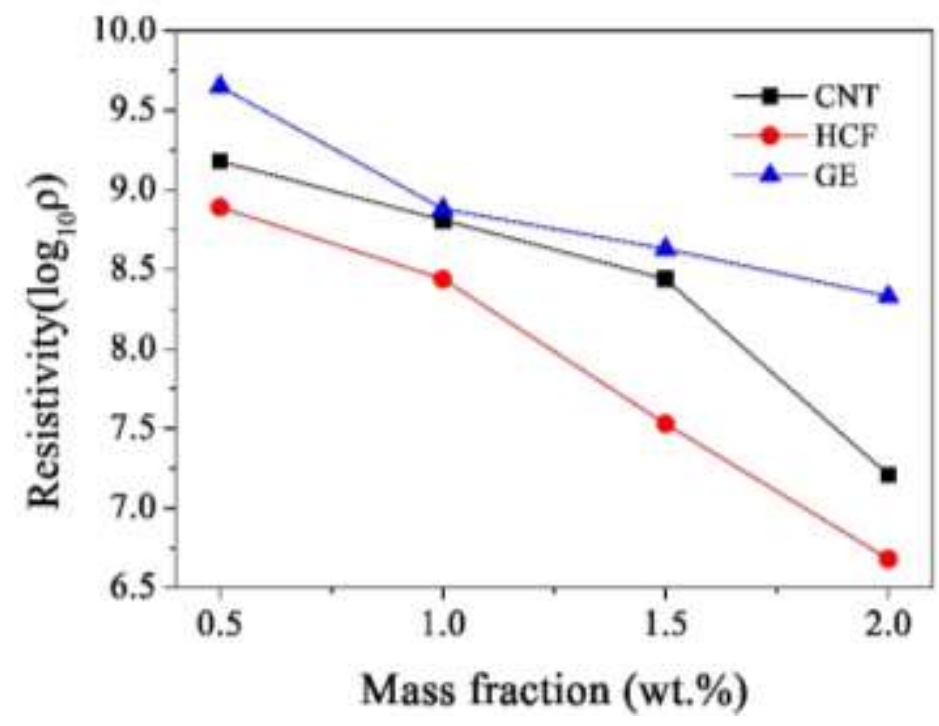

Fig. 8. Resistivity of gypsum composites filled with different carbon materials. 
The EM wave absorption properties and effective bandwidths $(\mathrm{RL}<-10 \mathrm{~dB})$ of the cylindrical periodic structured gypsum absorbers with different carbon absorbents are illustrated in Fig. 9 (a)-(c).
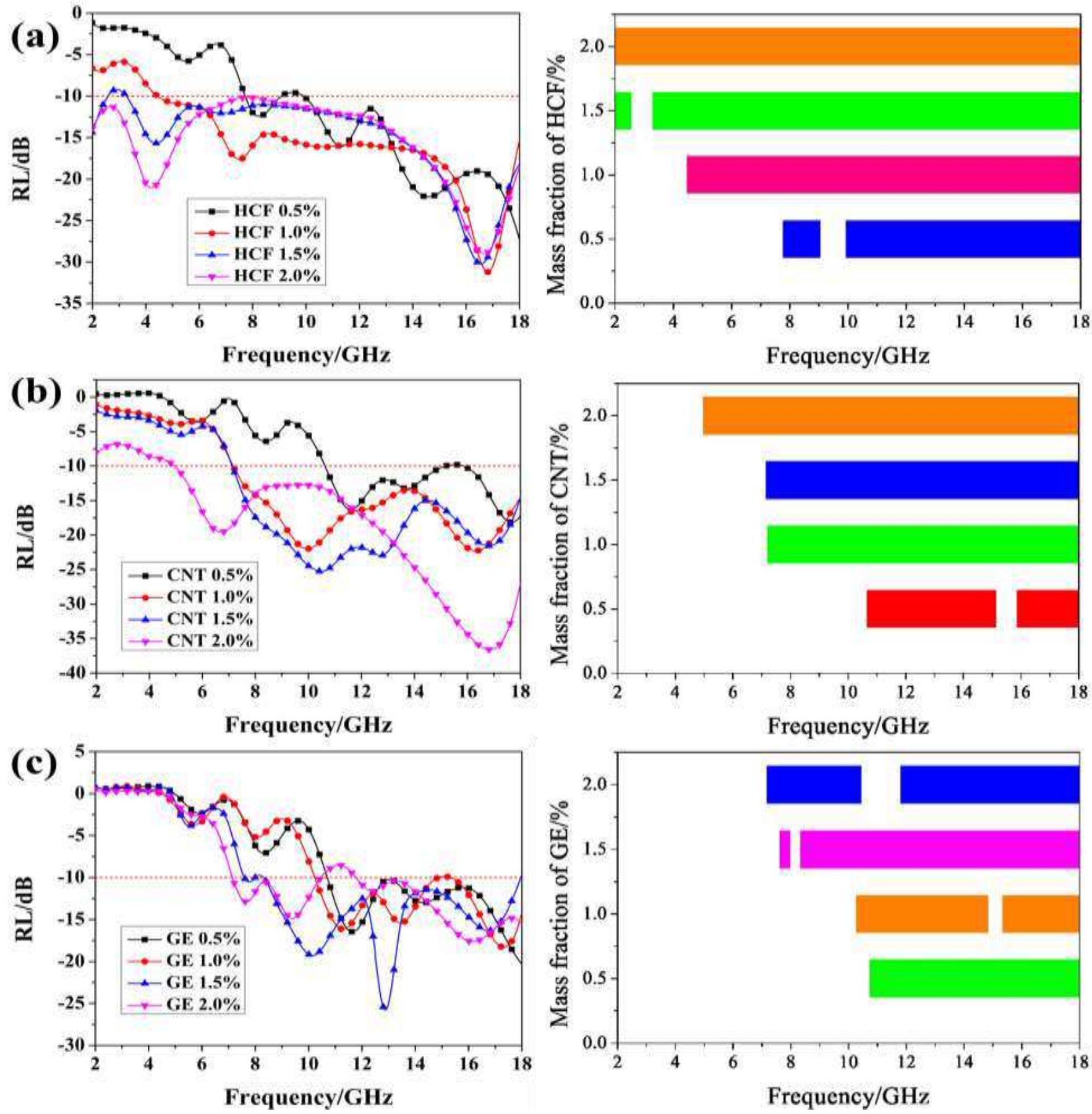

Fig. 9. The RL and effective bandwidth of the gypsum composites with different mass fraction of carbon materials: (a)

Gypsum composites with different HCF mass fraction; (b) Gypsum composites with different CNT mass fraction; (c) Gypsum composites with different GE mass fractions. 
Fig. 9 (a) shows the RL curves of the composites with different HCF mass fractions, it can be observed that the RL values can be influenced obviously by the variation of HCF mass fraction. Generally, the overall EM wave absorption performance keep increasing with the HCF mass fraction increases from 0.5 wt.\% to 2 wt.\%, as the effective bandwidth can be broadened continually. It should be noted that the RL values in the frequency range of 2-6 GHz decrease observably with the increase of HCF mass fraction. When the specimen with 2 wt.\% HCF, the minimum RL reaches $-21 \mathrm{~dB}$ at $4.2 \mathrm{GHz}$, and the RL values are less than $-10 \mathrm{~dB}$ in the whole 2-18 GHz frequency range.

The EM wave absorbing properties and effective bandwidth of the composites with different CNT mass fractions are presented in Fig. 9 (b). Similarly, with the CNT mass fraction increases from 0.5wt.\% to 2 wt.\%, the minimum RL value decreases and the effective bandwidth increases monotonously. The effective band shifts to lower frequency, however, the EM wave absorbing performance in lower frequency ranges of 2-5 $\mathrm{GHz}$ cannot be ideal. For the composite with 2 wt.\% CNT, its RL can be lower than $-10 \mathrm{~dB}$ in the frequency range of $5-18 \mathrm{GHz}$, and the minimum $\mathrm{RL}$ of $-36.6 \mathrm{~dB}$ is obtained at $16.9 \mathrm{GHz}$.

When the GE mass fraction of the composites varies from $0.5 \mathrm{wt} . \%$ to $2 \mathrm{wt} . \%$, the variation of RL and effective bandwidth are shown in Fig. 9 (c). It is obvious that the increase of GE mass fraction is beneficial to the enhancement of EM wave absorption in lower frequency. But the overall absorption bandwidth will be slightly reduced when the GE mass fraction reaches $2 \mathrm{wt} . \%$, which can be attributed to the locally developed conductive network formed by the laminar GE. For the composites with 2 wt.\% GE, the RL can be under -10 $\mathrm{dB}$ in $7.1-10.5 \mathrm{GHz}$ and $11.8-18 \mathrm{GHz}$, while the RL of the composites with 1.5 wt.\% GE is less than $-10 \mathrm{~dB}$ in 7.6-8 GHz and 8.3-18 GHz, and the minimum RL of $-25.7 \mathrm{~dB}$ can be attained in $12.9 \mathrm{GHz}$.

In general, the effective band can be moved to lower frequency range by increasing carbon absorbent mass fraction, and the comprehensive EM wave absorption capacity of above three kinds of carbon materials are arranged as $\mathrm{HCF}>\mathrm{CNT}>\mathrm{GE}$. As discussed in Ref [31], the first absorption peak of RL curve occurred in 
lower frequency could be caused by the destructive interference. According to the following equation, it is well expressed that the interference frequency is determined by the EM parameters and whole thickness [3537].

$$
f=n c / 4 t \sqrt{\varepsilon_{r} \mu_{r}}(n=1,3,5,7,9 \cdots)
$$

where, $f$ is the interference frequency, $t$ is sample thickness, $\varepsilon_{r}$ and $\mu_{r}$ are the relative permittivity and permeability, respectively. The thicknesses of the gypsum composites fabricated in this work are fixed at 20 $\mathrm{mm}$, thus the permittivity is the only factor for the movement of absorption peaks. The increase of permittivity will decrease the corresponding interference frequency, improving EM absorption properties in the lower frequency range. In addition, the difference between the EM wave absorption with three kinds of carbon absorbents can be attributed to their different dielectric loss abilities, as shown in Fig. 7.

\subsection{Analysis of EM wave absorbing mechanism}

Effective bandwidth and minimum RL of some reported typically gypsum absorbers for EM wave absorption are summarized in Table 3. In order to evaluate the EM wave absorbing properties of the absorbers with different thickness, a bandwidth thickness ratio coefficient $\gamma$ is defined as $\gamma=B / T$, where $B$ represents the effective bandwidth which is measured in GHz, $T$ is the thickness of EM wave absorber which is measured in mm. The $\gamma$ values of the gypsum absorbers listed in Table 3 were calculated, and the results are shown in Fig. 10.

According to Table 3 and Fig. 10, it can be found that the RL of slab structured gypsum composites can hardly reach $-10 \mathrm{~dB}$ in 2-18 GHz, and their values of $\gamma$ are lower than $0.23 \mathrm{GHz} / \mathrm{mm}$. The honeycomb and porous structures absorbers exhibit higher EM absorbing capacity in lower frequency range and possess wider effective bandwidth, their $\gamma$ can be $0.55 \mathrm{GHz} / \mathrm{mm}$ and $0.625 \mathrm{GHz} / \mathrm{mm}$, respectively. The 3D cylindrical periodic structured gypsum absorbers with different carbonaceous materials as absorbents show excellent EM wave absorbing performances. For the 3D cylindrical periodic structured absorber with $\mathrm{CB}$ and HCF, the RL 
can be under $-10 \mathrm{~dB}$ in the whole $2-18 \mathrm{GHz}$, and both of their $\gamma$ reach $0.8 \mathrm{GHz} / \mathrm{mm}$. Compared to the slab structured absorber, the CNT or GE modified absorber with 3D cylindrical periodic arrays possess larger bandwidth thickness ratio, which are less than those with $\mathrm{CB}$ and HCF as absorbents.

Table 3 EM wave absorption properties of some reported gypsum absorbers in 2-18 GHz

\begin{tabular}{|c|c|c|c|c|c|c|c|}
\hline \multirow{3}{*}{ Structure type } & \multirow{3}{*}{ Absorbent } & \multirow[t]{2}{*}{ Fraction } & \multirow[t]{2}{*}[RL]{$_{\min }$} & \multirow[t]{2}{*}{$F$} & \multirow[t]{2}{*}{$B$} & \multirow[t]{2}{*}{$T$} & \multirow{3}{*}{ Ref. } \\
\hline & & & & & & & \\
\hline & & $($ wt.\%) & $(\mathrm{dB})$ & $(\mathrm{GHz})$ & $(\mathrm{GHz})$ & $(\mathrm{mm})$ & \\
\hline Single layer & Graphite & 25 & -19.53 & 13.8 & 1 & 10 & {$[38]$} \\
\hline Single layer & Diatomite $/ \mathrm{Ni}_{0.5} \mathrm{Zn}_{0.5} \mathrm{Fe}_{2} \mathrm{O}_{4}$ & 15 & -6.12 & 11.7 & 1 & 10 & {$[39]$} \\
\hline Single layer & Graphite, ferrite & 20,30 & -23 & 3.2 & 2.3 & 10 & {$[40]$} \\
\hline Multi-layers & Carbon fiber & 2.8 & -27.08 & 2.35 & 1 & 15 & {$[41]$} \\
\hline Honeycomb structure & $\mathrm{CB}$ & 0.6 & -19 & 3.4 & 5.5 & 10 & {$[9]$} \\
\hline Porous structure & $\mathrm{CB}$ & 3 & -15 & 2 & 12.5 & 20 & {$[16]$} \\
\hline \multirow[t]{3}{*}{ Cylindrical periodic arrays } & $\mathrm{CB}$ & 2 & -27.3 & 16.3 & 16 & 20 & {$[31]$} \\
\hline & $\mathrm{HCF}$ & 2 & -21 & 4.2 & 16 & 20 & \\
\hline & & & & & & & This \\
\hline \multirow[t]{3}{*}{ Cylindrical periodic arrays } & CNT & 2 & -36.6 & 16.9 & 13 & 20 & \\
\hline & & & & & & & work \\
\hline & GE & 1.5 & -25.7 & 12.9 & 10.3 & 20 & \\
\hline
\end{tabular}

$[R L]_{\text {min }}$ : minimum reflection loss; $F$ : frequency at $[R L]_{\min } ; B$ : bandwidth of $R L$ under -10 dB; $T$ : total thickness of sample. 


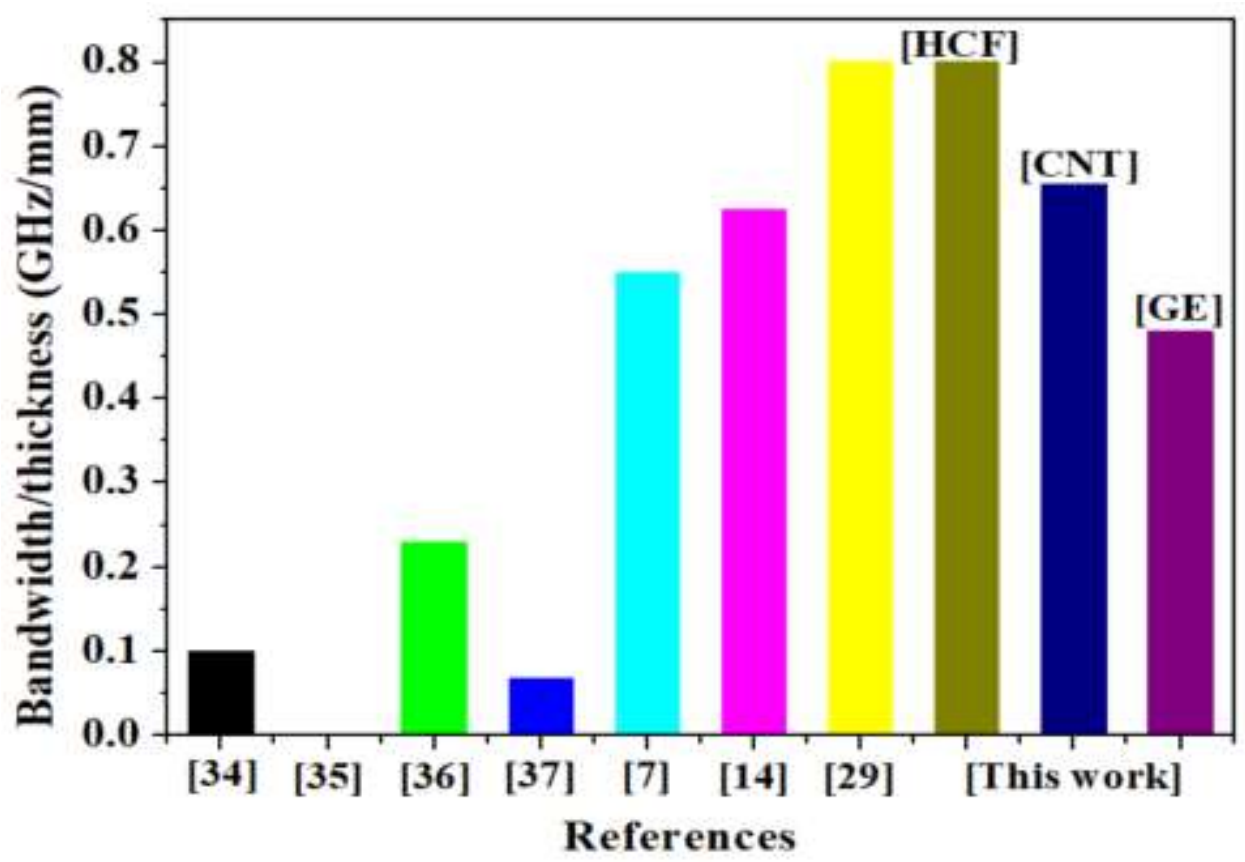

Fig. 10. Bandwidth thickness ratio coefficient of some reported gypsum composites and fabricated in this work.

The excellent EM wave absorption performance of the cylindrical periodic structured composites is the result of combination of the dielectric loss of carbonaceous materials and the structural effect of cylindrical periodic arrays. When the incident waves enter into the composites, the composites can dissipate the EM energy of the incident wave into heat by the dielectric loss of carbonaceous materials. For a dielectric loss composite, its attenuation constant $\alpha$ can be express as the following equation [42]

$$
\alpha=\sqrt{2} \pi f / c \times \varepsilon^{\prime} \mu^{\prime} \times \sqrt{\left(\tan \delta_{e}-1\right)+\sqrt{\left(\tan \delta_{e}-1\right)^{2}+\left(\tan \delta_{e}\right)^{2}}}
$$

where, $c$ is the speed of light, $f$ is the frequency, $\varepsilon^{\prime}$ and $\mu^{\prime}$ are the real part and imaginary part of permittivity, respectively, $\tan \delta_{e}$ represents the dielectric loss factor. The above equation indicates that the higher of the permittivity and dielectric loss factor leads to higher attenuation constant. As shown in Fig. 7, the gypsum composites with a same mass fraction of three kinds of carbonaceous materials exhibits different permittivity and dielectric loss factors, which can be arranged as $\mathrm{HCF}>\mathrm{CNT}>\mathrm{GE}$. According to the above equation, the gypsum composite with HCF as absorbent possesses the highest attenuation constant, which can be verified by the testing results of the RL shown in Fig. 9. Moreover, the HCF with chirality characteristic possesses extra EM wave attenuation mechanism compared to CNT and GE, including the cross polarization, induced 
current dissipation, and multi-interface scattering $[43,44]$.

Besides the dielectric loss of carbonaceous materials, the design of cylindrical periodic arrays plays an important role in the dissipation of incident waves. As discussed in our previous study [31], the first absorption peak at a lower frequency of the RL curve can be attributed to the destructive interference.

In order to further investigate the EM wave absorbing mechanism of the cylindrical periodic structured composites, the distribution of electric field, magnetic field, and power loss of the composites with 2 wt.\% different carbonaceous materials are simulated. Fig. 11 (a), (d) and (g) illustrate the electric distribution of the composites with 2 wt.\% HCF, CNT, and GE at $16.2 \mathrm{GHz}, 16.5 \mathrm{GHz}$, and $16.4 \mathrm{GHz}$, respectively. It can be seen that the electric field mainly distributes on the center and edge of top surface of the cylindrical array and the surface of the basal layer, and some on the lateral surface of the cylindrical array. The results indicate that the EM energy would be mainly attenuated on the top surface of cylindrical array by the EM wave diffraction and on the surface of basal layer by the destructive interference. In addition, the multiple refractions of EM waves would also be occurred between the adjacent arrays, which makes a contribution to the EM wave attenuation. As shown in Fig. 11 (b), (e) and (h), the magnetic field of the three composites mainly concentrated in the basal layer, and can be rarely found in other areas. The areas of power loss distributions of the three composites and their electric field distributions overlap each other, respectively, further confirming the major EM loss of the composites fabricated in this work derive from electric loss. Furthermore, the discrete cylindrical periodic arrays can be regarded as a series equivalent capacitance, improving the impedance matching condition of the composites, which is beneficial to the enhancement of EM wave absorption performance [26]. 


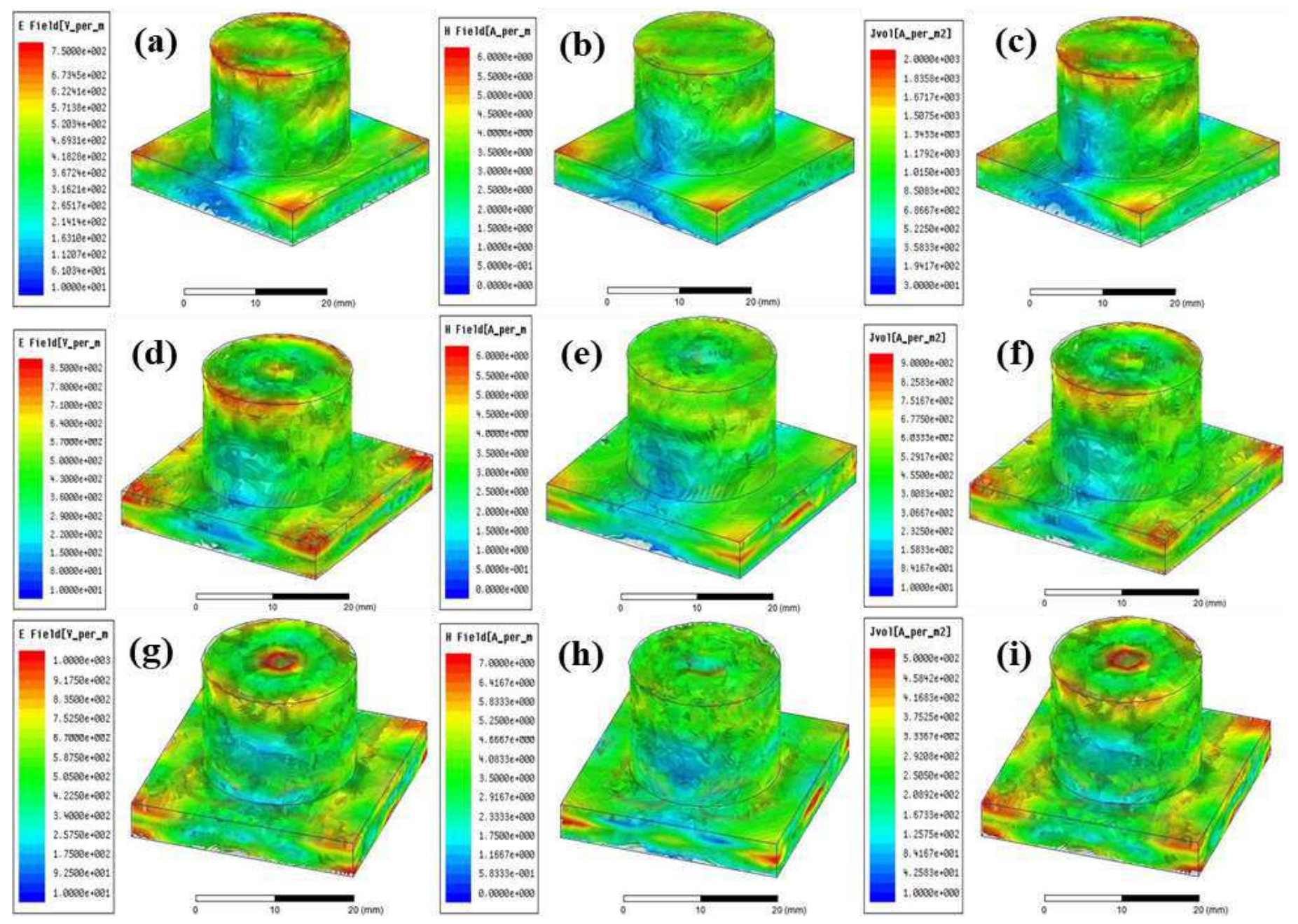

Fig. 11. The distribution of electric field ( $a, d, g)$, magnetic field (b, e, h), and power loss (c, f, i) of the gypsum composites with 2 wt.\% carbonaceous materials: (a-c) the composites with 2 wt.\% HCF; (d-f) the composites with 2 wt.\% CNT; (g-i) the composites with 2 wt.\% GE.

\subsection{Mechanical properties of gypsum composites incorporate with different carbonaceous materials}

The flexural strength of the gypsum composites incorporate with different carbon materials is shown in Fig. 12. It can be seen that the flexural strength of pure gypsum used in this work is $7.1 \mathrm{MPa}$. The flexural strength of gypsum matrix can be decreased obviously by introducing CNT and GE, when the mass fraction of CNT and GE variation from $0.5 \%$ to $2 \%$. When the HCF mass fraction is $0.5 \%$, the gypsum matrix can be slightly strengthened, the flexural strength reaches 7.5 MPa. However, with the further increase of HCF mass fraction, the flexural strength will be decreased. It also can be found that the order of the influence degree of 
three carbon materials on the flexural strength of gypsum matrix is GE $>\mathrm{CNT}>\mathrm{HCF}$.

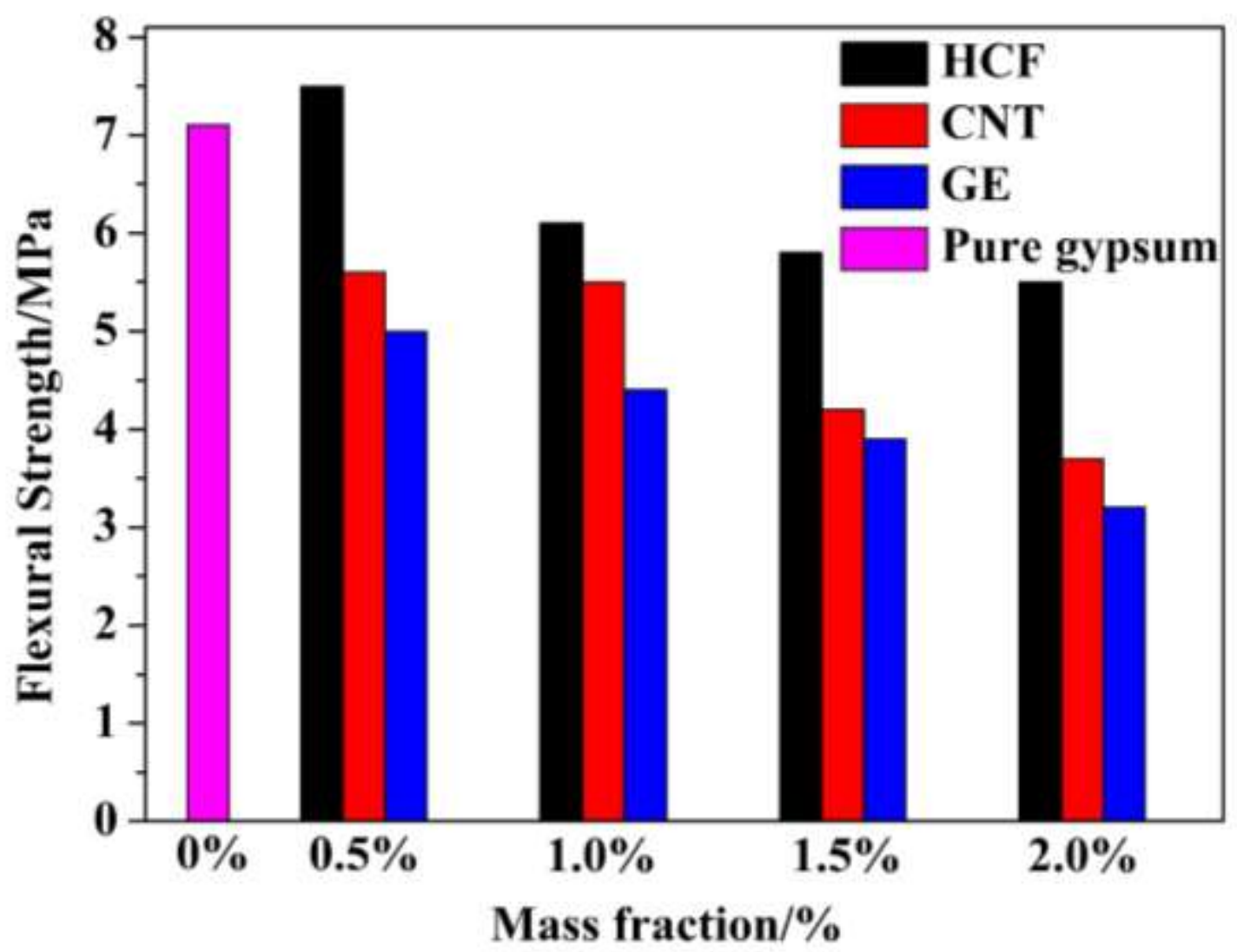

Fig. 12. The effects of different carbon materials on the flexural strength of gypsum matrix.

\section{Conclusions}

In this study, the EM parameters and wave absorption properties of cylindrical periodic structured gypsum composites with different carbonaceous absorbents were comparative experimental investigated. The results indicate that the orders of increasing rates of both the conductivity and complex permittivity of the composites with same mass fraction are $\mathrm{HCF}>\mathrm{CNT}>\mathrm{GE}$, and their variation of EM wave absorbing properties shows the same regularity. The gypsum composite with $2 \%$ HCF possesses optimum EM absorbing performance, its RL values can be less than $-10 \mathrm{~dB}$ in 2-18 GHz and bandwidth thickness ratio coefficient reaches $0.8 \mathrm{GHz} / \mathrm{mm}$. The simulation results of EM field and power loss distribution shows the EM wave absorbing mechanism of the fabricated cylindrical periodic structured composites can be attributed to the dielectric loss of carbonaceous absorbents, the destructive interference, the EM wave diffraction and multiple 
refractions caused by the $3 \mathrm{D}$ periodic arrays. The proposed gypsum composites possesses broadband absorption characteristic with great potential application in EM radiation protection and treatment.

\section{Acknowledgements}

Financial support from the Pre-research and Exploration Projects of State Key Laboratory of Green Building Materials (No. ZA-23 and No. ZA-4).

\section{Conflict of interest}

The authors declare that they have no conflict of interest.

\section{References}

[1] Liang XH, Man ZM, Quan B, Zheng J, Gu WH, Zhang Z, Ji GB (2020) Environment-Stable $\mathrm{Co}_{\mathrm{x}} \mathrm{Ni}_{\mathrm{y}}$ Encapsulation in Stacked Porous Carbon Nanosheets for Enhanced Microwave Absorption. Nano-Micro Lett 12, 102.

[2] He GH, Duan YP, Pang HF (2020) Microwave Absorption of Crystalline Fe/MnO@C Nanocapsules Embedded in Amorphous Carbon. Nano-Micro Lett 12, 57.

[3] Wang ZJ, Zhang T, Zhou L (2016) Investigation on electromagnetic and microwave absorption properties of copper slagfilled cement mortar. Cement Concrete Comp 74: 174-181.

[4] He YJ, Lu LN, Sun KK, Wang FZ, Hu SG (2018) Electromagnetic wave absorbing cement-based composite using Nano$\mathrm{Fe}_{3} \mathrm{O}_{4}$ magnetic fluid as absorber. Cement Concrete Comp 92: 1-6.

[5] Nam IW, Choi JH, Kim CG, Lee HK (2018) Fabrication and design of electromagnetic wave absorber composed of carbon nanotube-incorporated cement composites. Compos Struct 15: 439-447.

[6] Zhang LQ, Li LW, Wang YL, Yu X, Han BG (2020) Multifunctional cement-based materials modified with electrostatic self-assembled CNT/TiO 2 composite filler. Constr Build Mater 238 (30): 117787.

[7] Younes L, Ratiba B, Azzedine A, Laurent LG, Aicha EA (2020) Glass foam composites based on tire's waste for microwave absorption application. J Non-Cryst Solids 537: 120017.

[8] Yao R, Liao SY, Dai CL, Yang Y, Zheng F (2014) Dual functions of novel glass-ceramic floor tile design and preparation. 
Ceram Int 40 (6): 8667-8675.

[9] Xie S, Ji ZJ, Yang Y, Hou GY, Wang J (2016) Electromagnetic wave absorption properties of honeycomb structured plasterboards in S and C bands. J Build Eng 7: 217-223.

[10] Li M, Yin XW, Chen LQ, Han MK, Cheng LF, Zhang LT (2016) Dielectric and electromagnetic wave absorption properties of reduced graphene oxide/barium aluminosilicate glass-ceramic composites. Ceram Int 42 (6): 7099-7106.

[11] Zhang ZH, Wang CD, Zhang YH, Xie JX (2010) Microwave absorbing properties of composites filled with glass-coated $\mathrm{Fe}_{69} \mathrm{Co}_{10} \mathrm{Si}_{8} \mathrm{~B}_{13}$ amorphous microwire. Mater Sci Eng B-Adv 175 (3): 233-237.

[12] Xie S, Yang Y, Hou GY, Wang J, Ji ZJ (2016) Development of layer structured wave absorbing mineral wool boards for indoor electromagnetic radiation protection. J Build Eng 5: 79-85.

[13] Sun JB, Huang YM, Aslani F, Ma GW. (2020) Properties of a double-layer EMW-absorbing structure containing a graded nano-sized absorbent combing extruded and sprayed 3D printing. Constr Build Mater 261: 120031.

[14] Zhang XZ, Sun W (2012) Preparation and microwave absorbing properties of three-layered cement-based composites. Procedia Eng, 27: 348-356.

[15] Omid K, Morteza ZS, Karl A, Plamen S (2017) The structural, magnetic and microwave properties of spherical and flake shaped carbonyl iron particles as thin multilayer microwave absorbers. J Magn Magn Mater 428: 28-35.

[16] Xie S, Ji ZJ, Yang Y, Hou GY, Wang J (2016) Electromagnetic wave absorption enhancement of carbon black/gypsum based composites filled with expanded perlite. Compos Part B-Eng 106: 10-19.

[17] Wang ZY, Wang Z, Ning M (2020) Optimization of electromagnetic wave absorption bandwidth of cement-based composites with doped expanded perlite. Constr Build Mater 259: 119863.

[18] Li BY, Duan YP, Zhang YF, Liu SH (2011) Electromagnetic wave absorption properties of cement-based composites filled with porous materials. Mater Design 32 (5): 3017-3020.

[19] Lv XJ, Duan YP, Chen GQ (2018) Electromagnetic wave absorption properties of cement-based composites filled with graphene nano-platelets and hollow glass microspheres. Constr Build Mater 162: 280-285. 
[20] Li B, Ji ZJ, Xie S, Wang J, Zhou JB, Zhu LC (2019) Electromagnetic wave absorption properties of carbon black/cementbased composites filled with porous glass pellets. J Mater Sci-Mater El 30: 12416-12425.

[21] Yang D, Yin YF, Zhang ZK, Li DC, Cao Y (2020) Wide-angle microwave absorption properties of multilayer metamaterial fabricated by 3D printing. Mater Lett DOI: doi.org/10.1016/j.matlet.2020.128571.

[22] Cui JL, Zhang BZ, Xu HC, Sun HX, Shao GR (2019) Topological flexible metamaterials with isotropic dual-frequency terahertz-band absorption. Opt Commun 441: 90-95.

[23] Wang CX, Chen MJ, Lei HS, Zeng ZH, Yao K, Yuan XJ, Fang DN (2020) Frequency-selective-surface based sandwich structure for both effective loadbearing and customizable microwave absorption. Compos Struct 235: 111792.

[24] Huang HM, Wang W, Hua MY, Kuang JC, Ma Y, Guo ZH, Xie W (2020) Broadband radar absorbing characteristic based on periodic hollow truncated cone structure. Physica B 595: 412368.

[25] Ning J, Dong SF, Luo XY, Chen K, Zhao JM, Jiang T, Feng YJ (2020) Ultra-broadband microwave absorption by ultrathin metamaterial with stepped structure induced multi-resonances. Results Phys DOI: doi.org/10.1016/j.rinp.2020.103320.

[26] Li WC, Li CS, Lin LH, Wang Y, Zhang JS (2019) All-dielectric radar absorbing array metamaterial based on silicon carbide/carbon foam material. J Alloy Compd 781: 883-891.

[27] Chen XQ, Wu Z, Zhang ZL, Zou YH (2020) Ultra-broadband and wide-angle absorption based on 3D-printed pyramid. Opt Laser Technol 124: 105972.

[28] Huang YX, Song WL, Wang CX, Xu YN, Wei WY, Chen MJ, Tang LQ, Fang DN (2018) Multi-scale design of electromagnetic composite metamaterials for broadband microwave absorption. Compos Sci Technol 162: 206-214.

[29] Zhou Q, Yin XW, Ye F, Liu XF, Cheng LF, Zhang LT (2017) A novel two-layer periodic stepped structure for effective broadband radar electromagnetic absorption. Mater Design 123: 46-53.

[30] Fan QF, Huang YX, Chen MJ, Lia Y, Song WL, Fang DN (2019) Integrated design of component and configuration for a flexible and ultrabroadband radar absorbing composite. Compos Sci Technol 176: 81-89. 
[31] Xie S, Zhu LC, Zhang Y, Ji ZJ, Wang J (2020) Three-dimensional periodic structured absorber for broadband electromagnetic radiation absorption. Electro Mater Letter 16: 340-346.

[32] Liu J, Duan YP, Song LL, Hu JJ, Zeng YS (2019) Heterogeneous nucleation promoting formation and enhancing microwave absorption properties in hierarchical sandwich-like polyaniline/grapheme oxide induced by mechanical agitation. Compos Sci Technol 182: 107780.

[33] Lee SE, Choi O, Hahn HT (2008) Microwave properties of graphite nanoplatelet/epoxy composites. J Appl Phys 104: 033705 .

[34] Anna AB, Gaetano L, Matteo DA, Domenico A (2006). Carbon black/silicone rubber blends as absorbing materials to reduce Electro Magnetic Interferences (EMI). Polym Bull 57: 587-593.

[35] Wang T, Han R, Tan GG, Wei JQ, Qiao L, Li FS (2012) Reflection loss mechanism of single layer absorber for flakeshaped carbonyl-iron particle composite. J Appl Phys 112 (10): 104903.

[36] Song LL, Duan YP, Liu J, Pang HF (2020) Transformation between nanosheets and nanowires structure in MnO2 upon providing Co2+ ions and applications for microwave absorption. Nano Research 13: 95-104.

[37] Cheng Y, Seow JZY, Zhao HQ, Xu ZCJ, Ji GB (2020) A Flexible and Lightweight Biomass-Reinforced Microwave Absorber. Nano-Micro Lett. 12, 125.

[38] Han CX, Shen WT, Gan YL, Cui SP (2017) Preparation and prop- erties of graphite gypsum absorbing composite materials. B Chin Ceram Soc 36(08): 2583-2588.

[39] Cui SP, Wang N, Guo HX, Ma XY (2016) Synthesis and elec-tromagnetic properties of nickel zinc ferrite coated on surface of diatomite. J Chin Ceram Soc 44(10): 1509-1514.

[40] Wang PQ, Wang Y, Zhang M, Tan DJ, Li YK (2015) Preparation and study on a new type of anti-electromagnetic radiation gypsum board. Appl Mech Mater 703: 90-93.

[41] Dong YF, Zhou L, Hao WJ, Yi YY, Zhao HC, Yu XD (2014) The study of absorbing property of $\lambda / 4$ type absorber made of carbon fiber membrane and gypsum board. Adv Mater Res 1030-1032: 236-240. 
[42] Shah A, Wang YH, Huang H, Zhang L, Wang DX, Zhou L, Duan YP, Dong XL, Zhang ZD (2015) Microwave absorption and flexural properties of Fe nanoparticle/carbon fiber/epoxy resin composite plates. Compos Struct 131: 1132-1141.

[43] Motojima S, Noda Y, Hoshiya S, Hishikawa Y (2003) Electromagnetic wave absorption properties of carbon microcoils in 12-110 GHz region. J Appl Phys 94(4): 2325-2330.

[44] Motojima S, Hoshiya S, Hishikawa Y (2003) Electromagnetic wave absorption properties of carbon microcoils/PMMA composite beads in W bands. Carbon 41: 2658-60. 


\section{Figures}

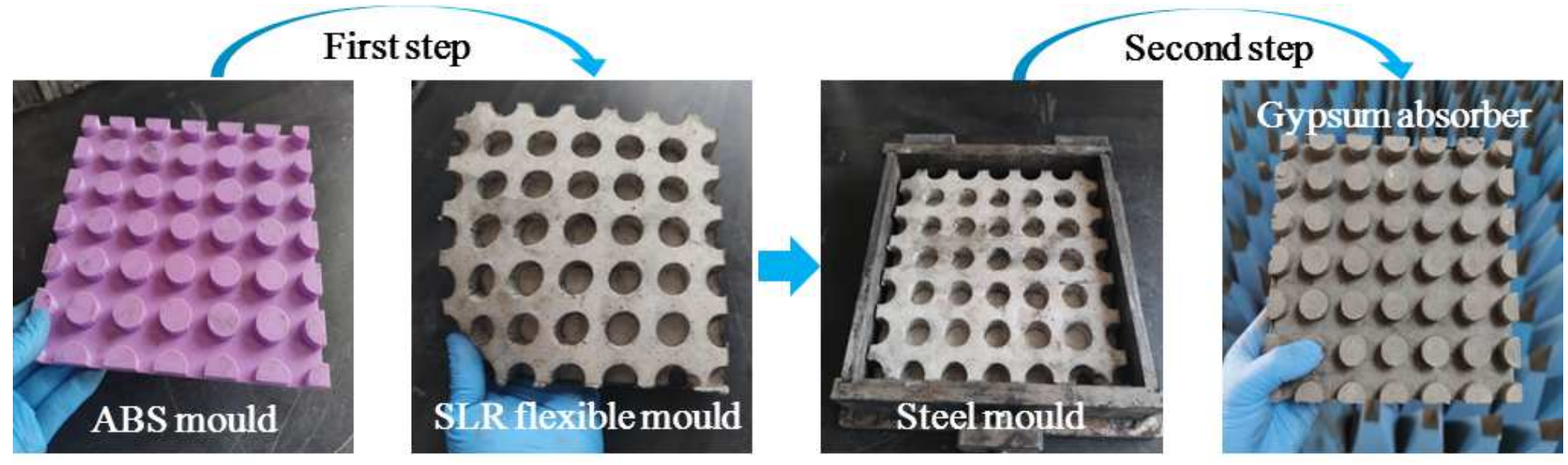

\section{Figure 1}

The procedures of cylindrical periodic structured gypsum absorber fabrication.

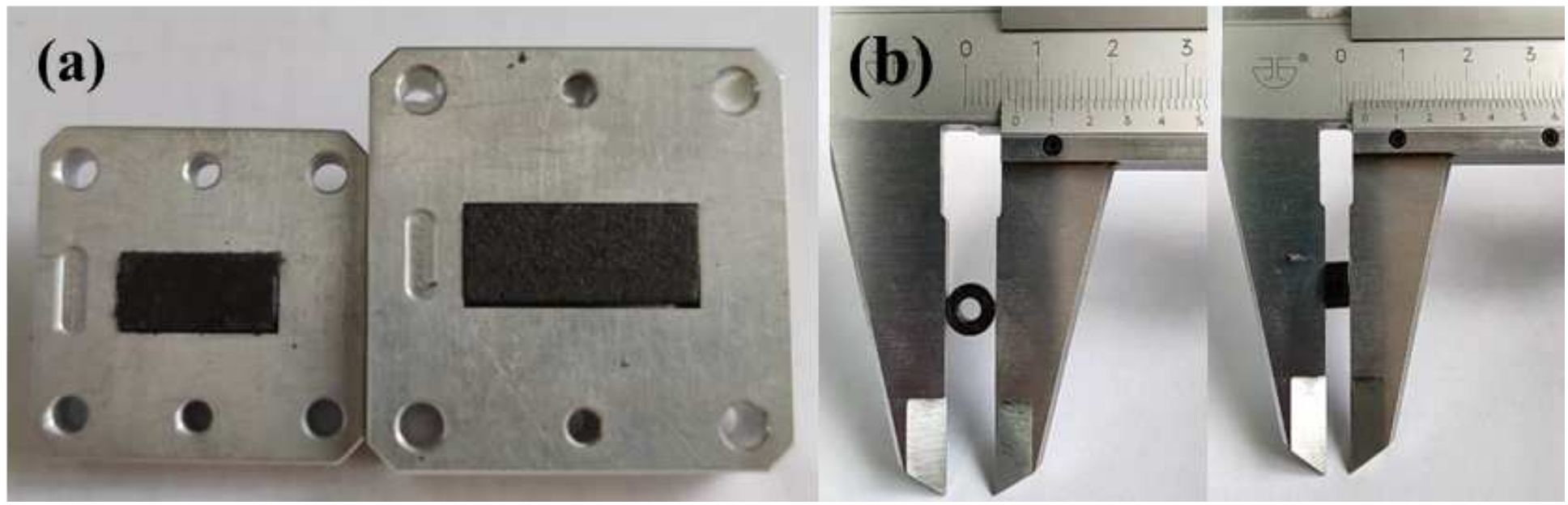

Figure 2

Photograph of the samples for waveguide method (a) and coaxial method (b). 

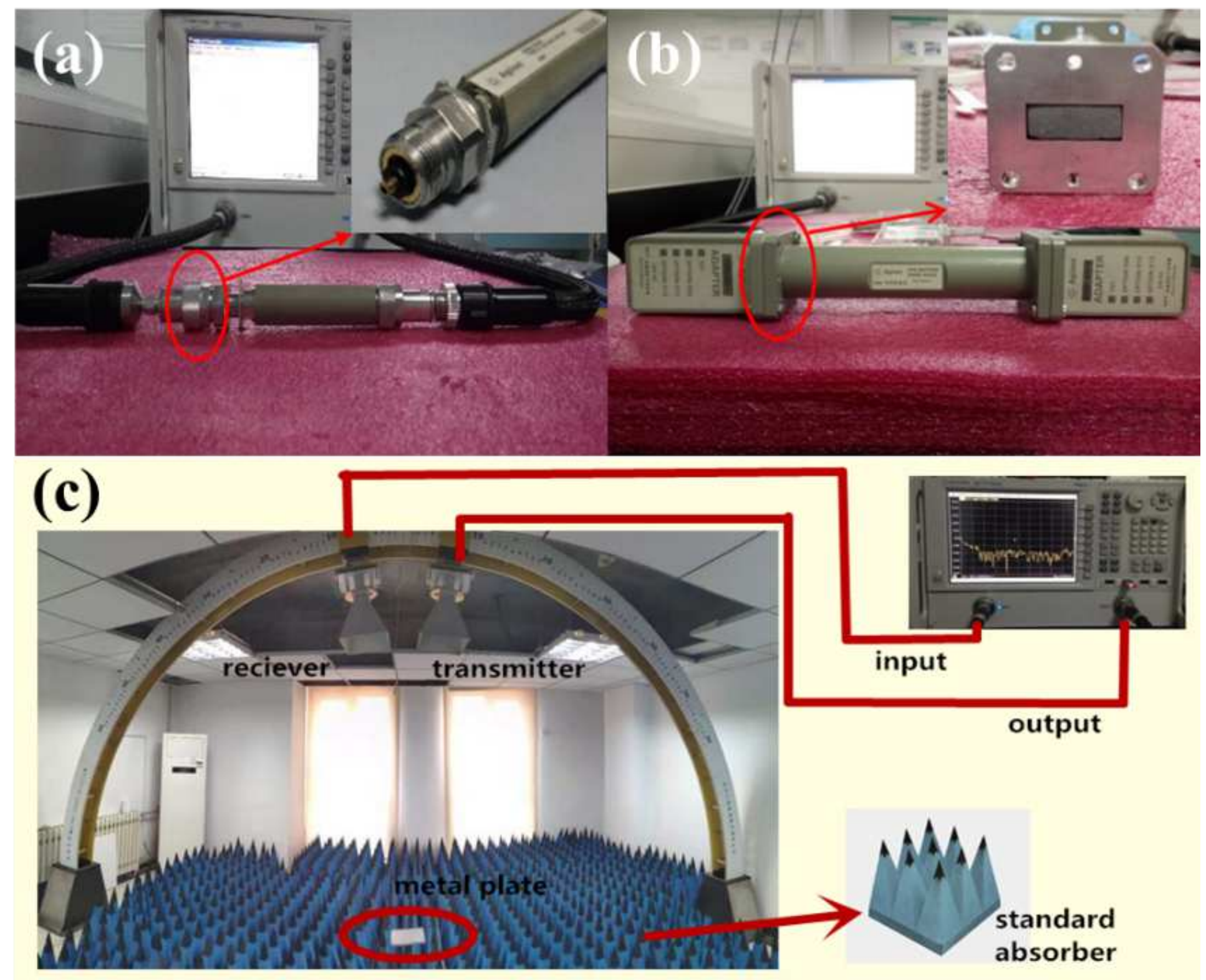

Figure 3

Testing system of coaxial method (a), waveguide method (b) and arch method system (d).

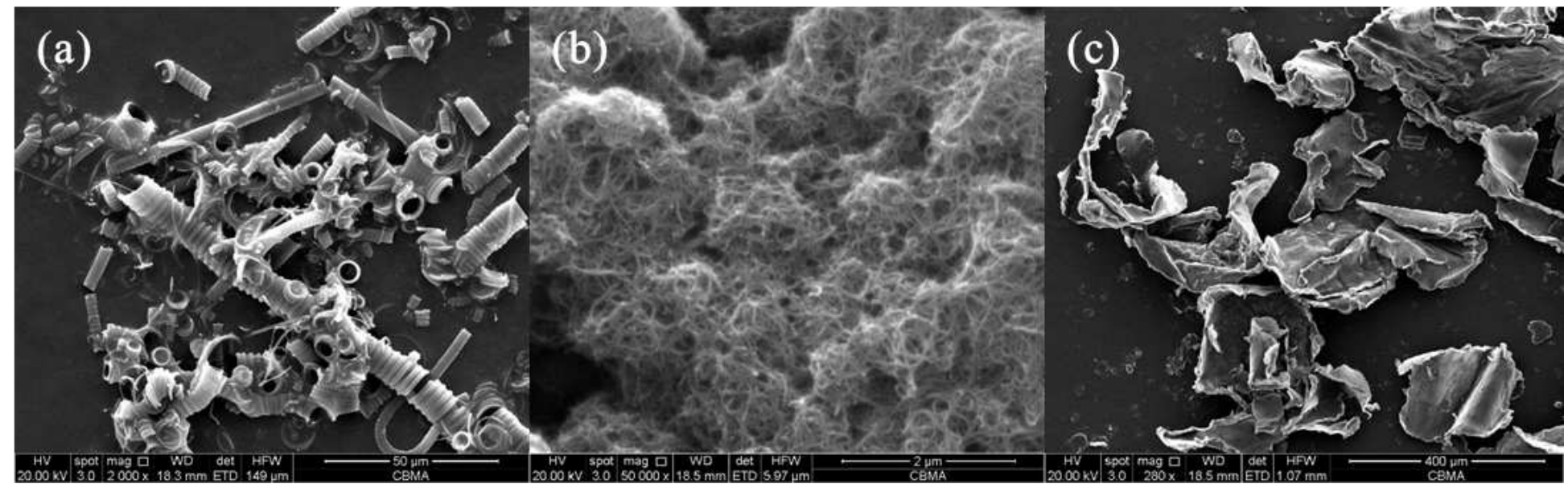


Figure 4

SEM images of HCF (a), CNT (b) and GE (c).
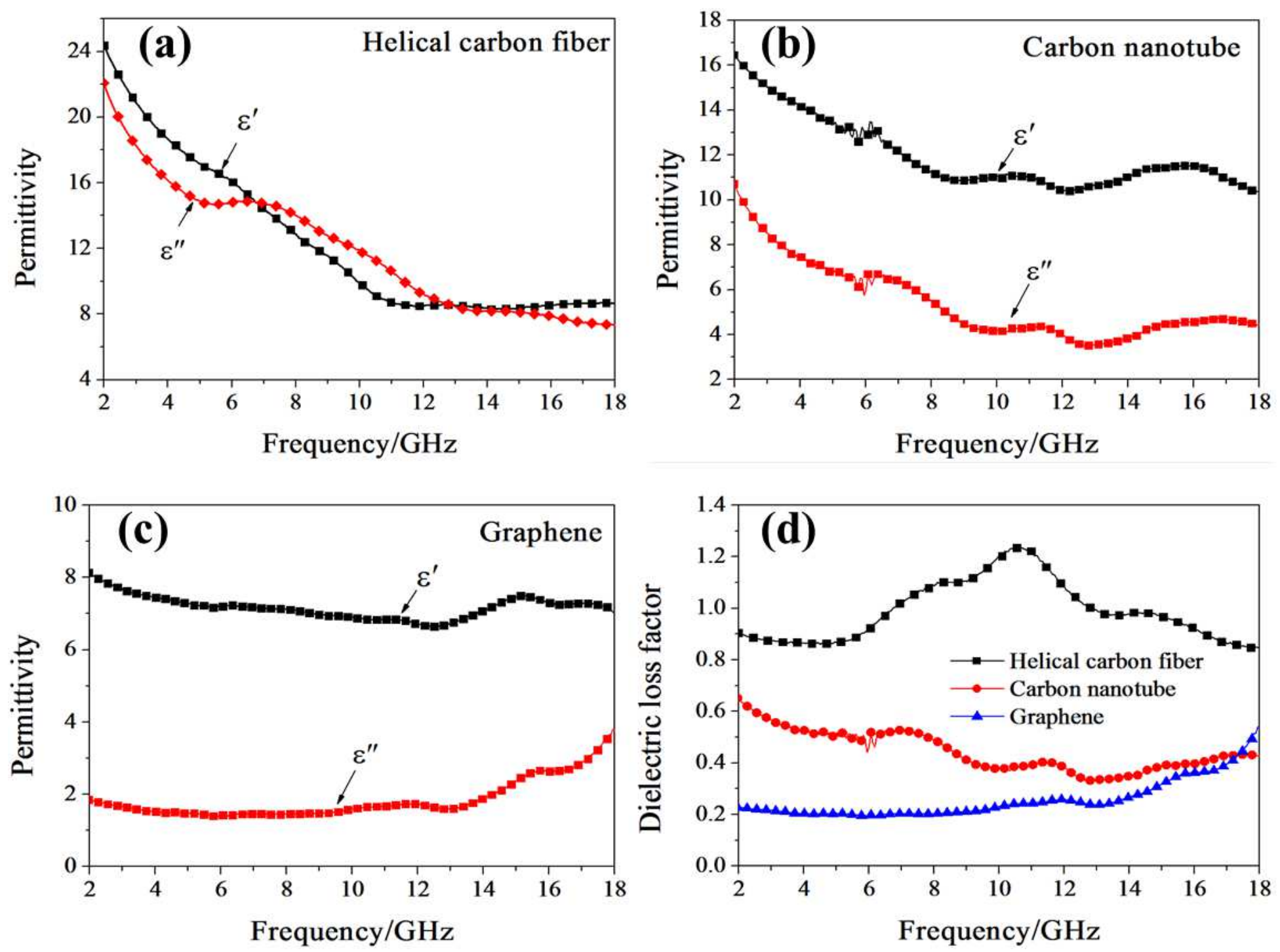

Figure 5

Permittivity and dielectric loss factor of different carbon materials: (a) Permittivity of HCF; (b) Permittivity of CNT; (c) Permittivity of GE; (d) Dielectric loss factor of three kinds of carbon materials. 


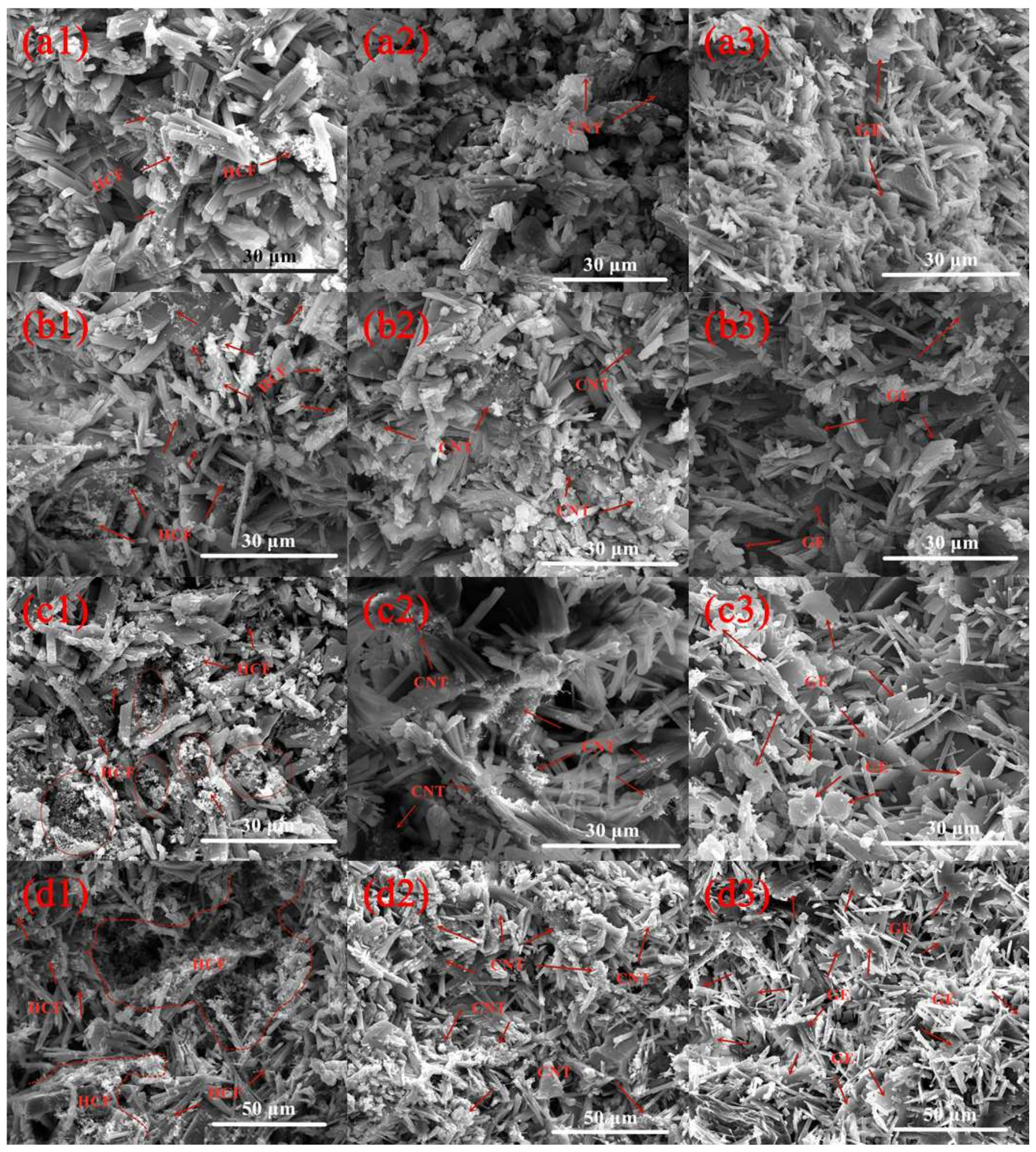

Figure 6

SEM images of gypsum composites with different carbon materials: (a1)-(d1) composites with 0.5 wt.\%, 1 wt.\%, 1.5 wt.\%, and 2 wt.\% HCF; (a2)-(d2) composites with 0.5 wt.\%, 1 wt. \%, 1.5 wt.\%, and 2 wt.\% CNT; (a3)-(d3) composites with 0.5 wt.\%, 1 wt.\%, 1.5 wt.\%, and 2 wt.\% GE. 

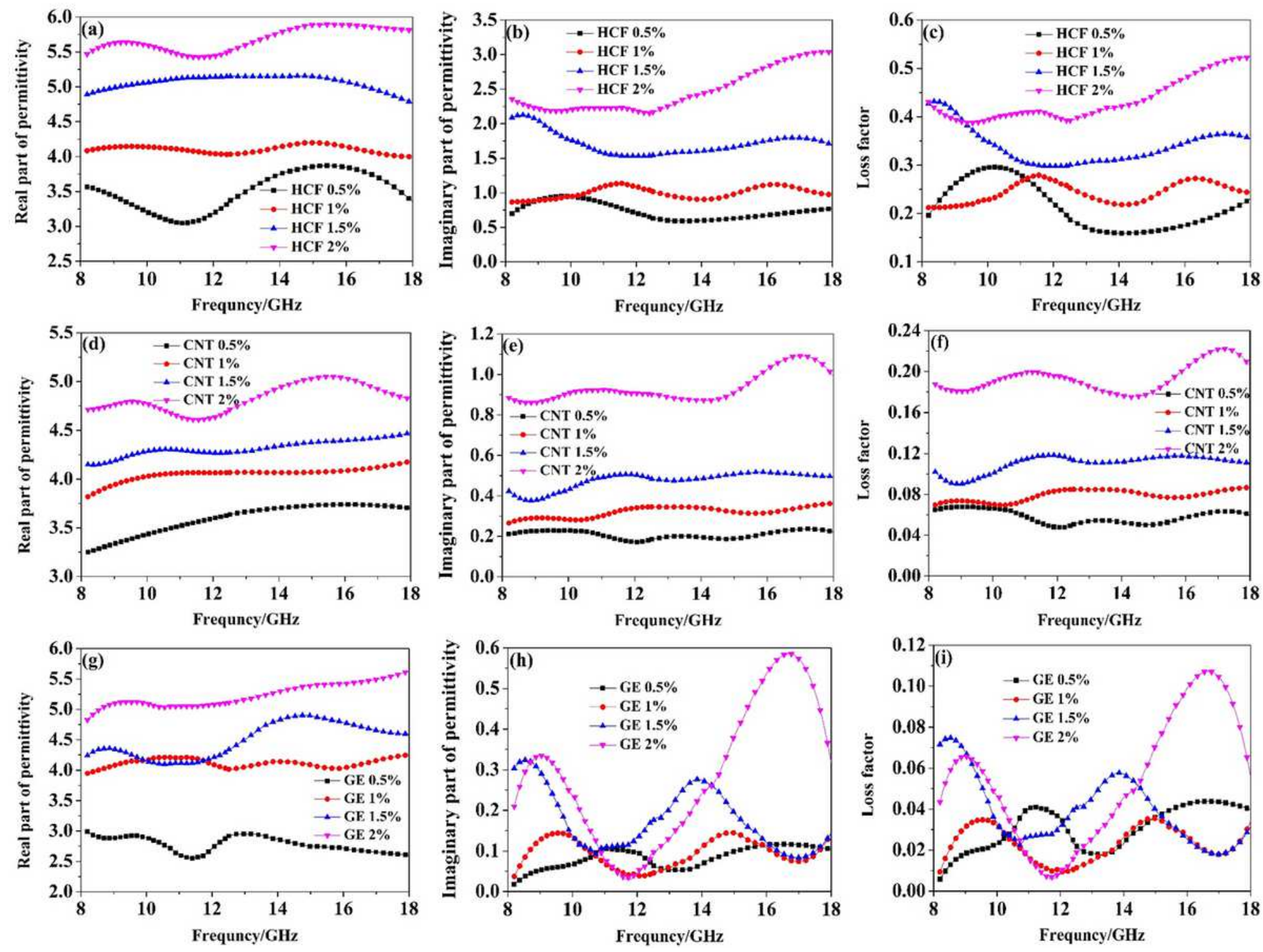

Figure 7

Permittivity and loss factor of gypsum based composites with different carbon materials: (a) (c) $\varepsilon^{\prime}, \varepsilon^{\prime \prime}$ and loss factor of HCF/gypsum composites; (d) (f) $\varepsilon^{\prime}, \varepsilon^{\prime \prime}$ and loss factor of CNT/gypsum composites; (g) (i) $\varepsilon^{\prime}, \varepsilon^{\prime \prime}$ and loss factor of GE/gypsum composites. 


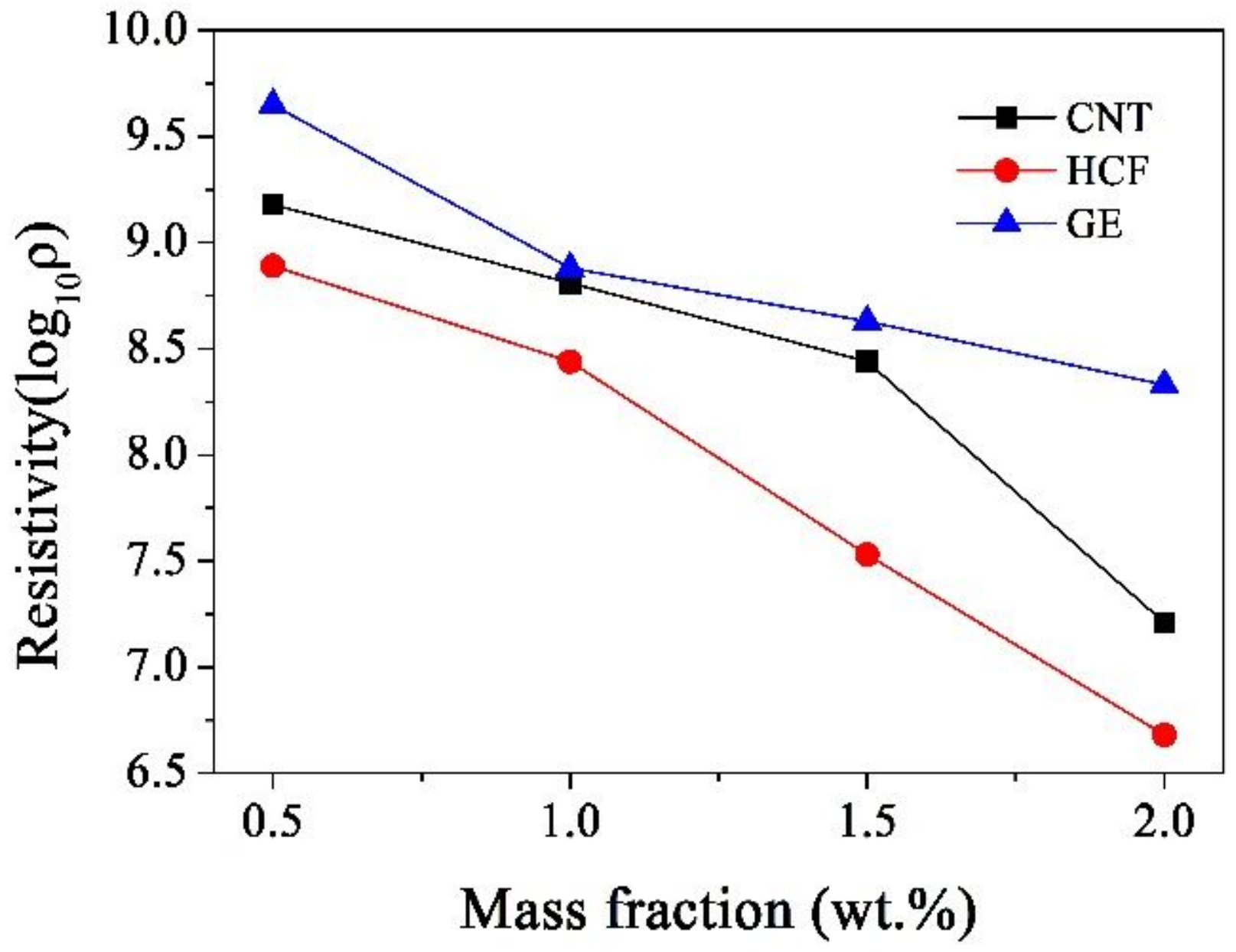

Figure 8

Resistivity of gypsum composites filled with different carbon materials. 

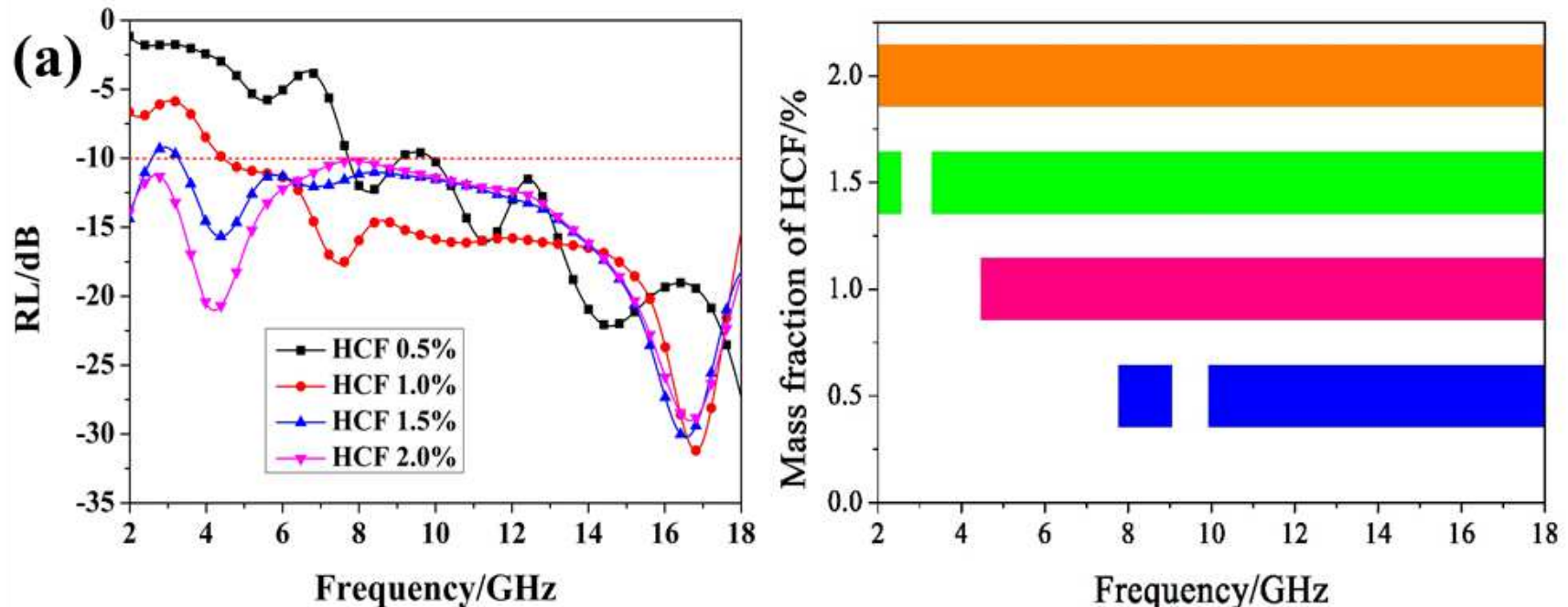

Frequency/GHz

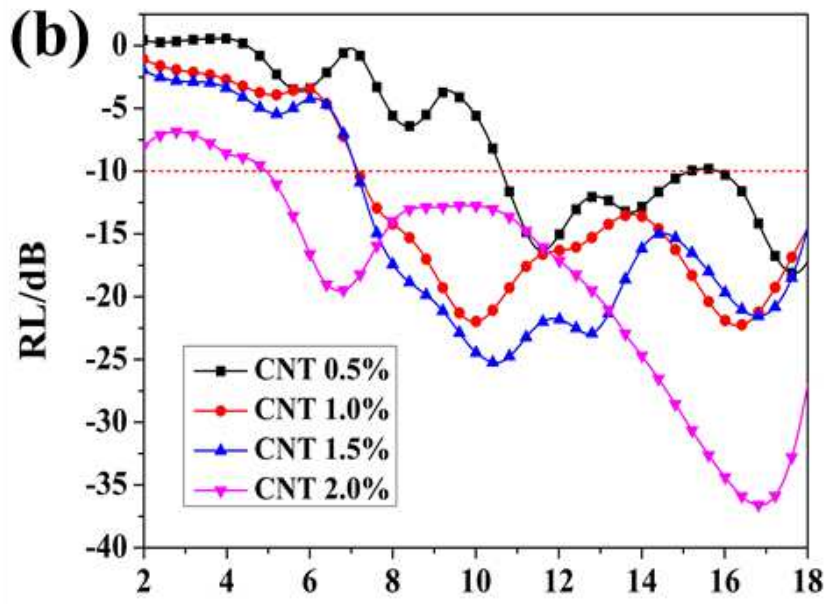

Frequency/GHz
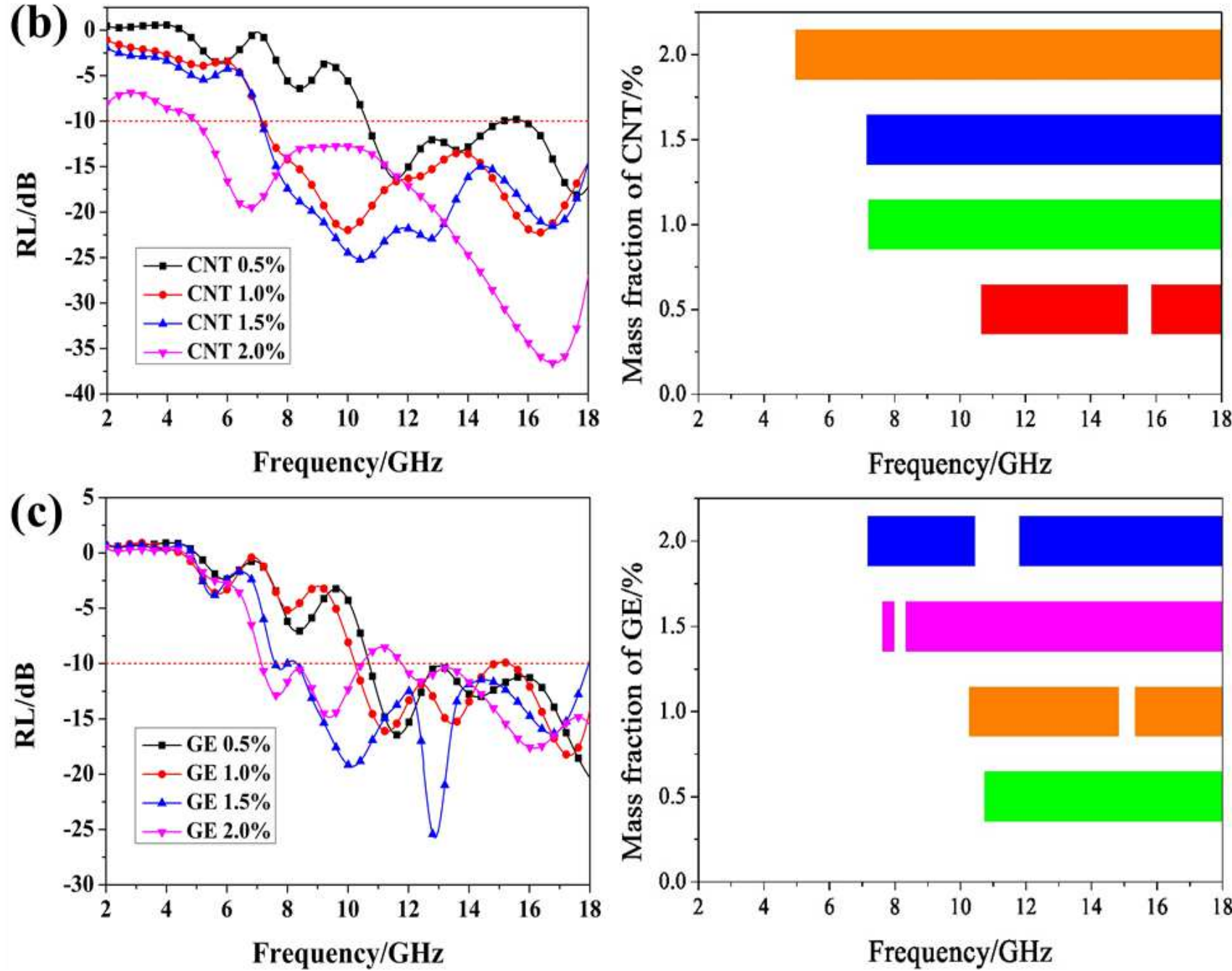

Frequency/GHz

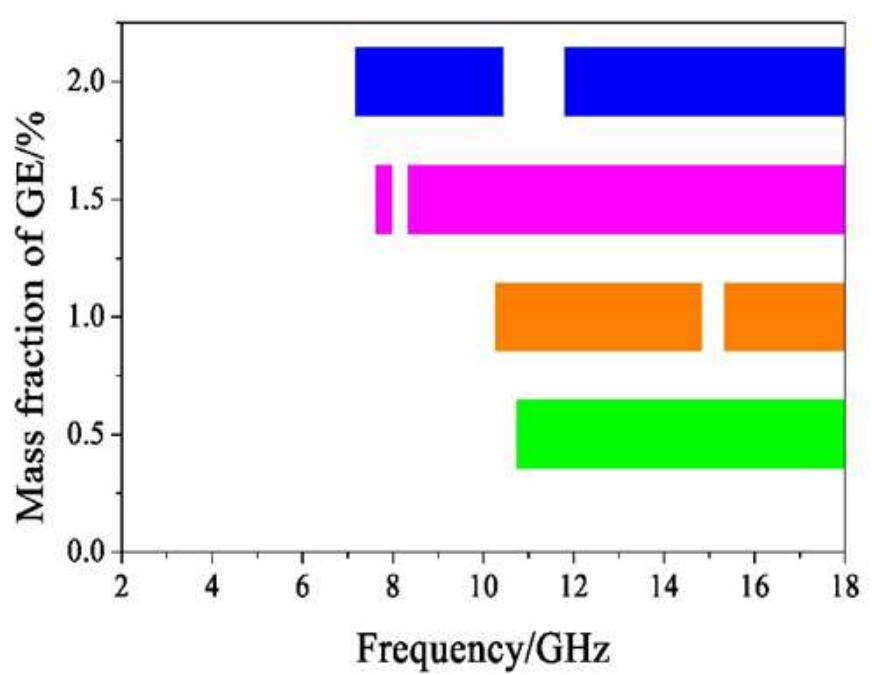

Figure 9

The RL and effective bandwidth of the gypsum composites with different mass fraction of carbon materials: (a) Gypsum composites with different HCF mass fraction; (b) Gypsum composites with different CNT mass fraction; (c) Gypsum composites with different GE mass fractions. 


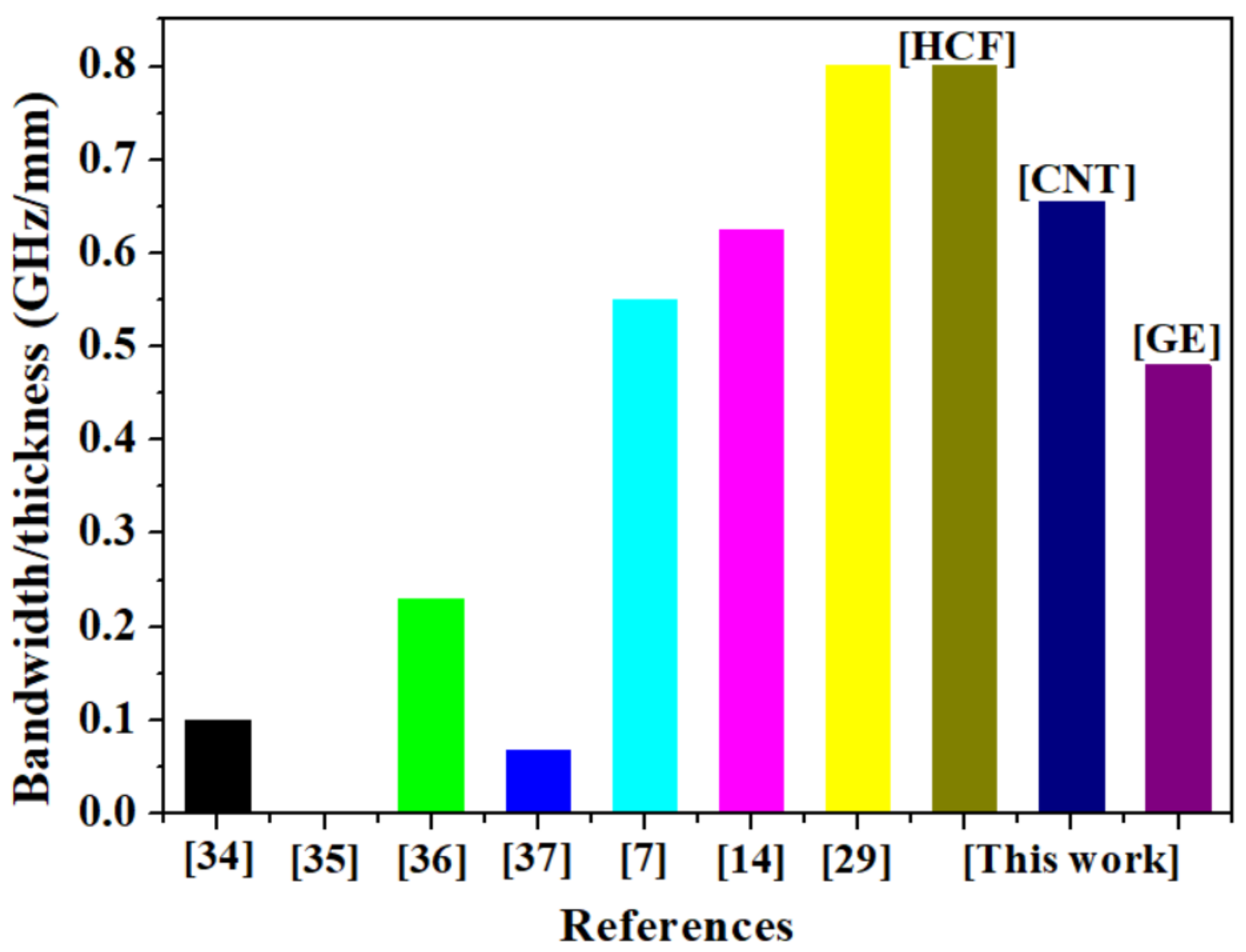

Figure 10

Bandwidth thickness ratio coefficient of some reported gypsum composites and fabricated in this work. 

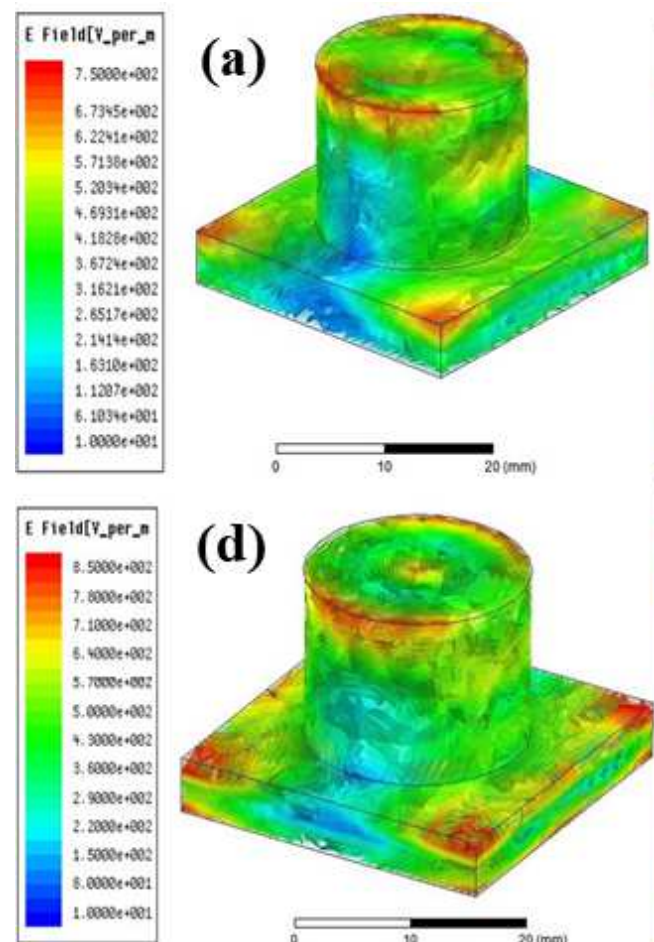

E Fiela[v_per_o
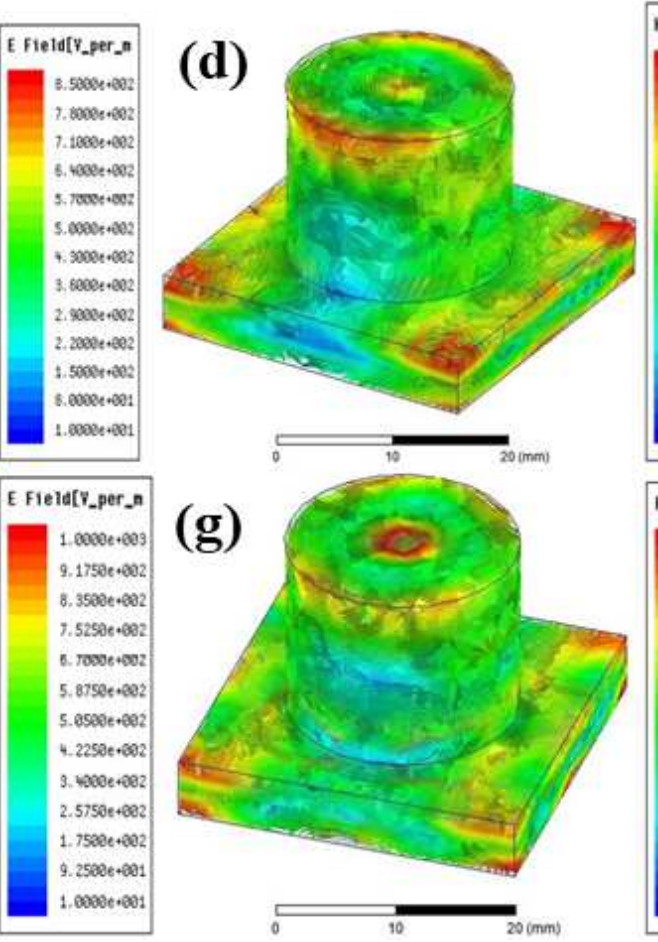
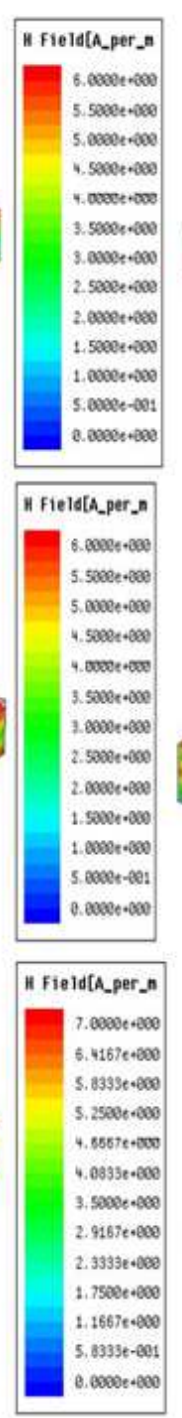

(b)
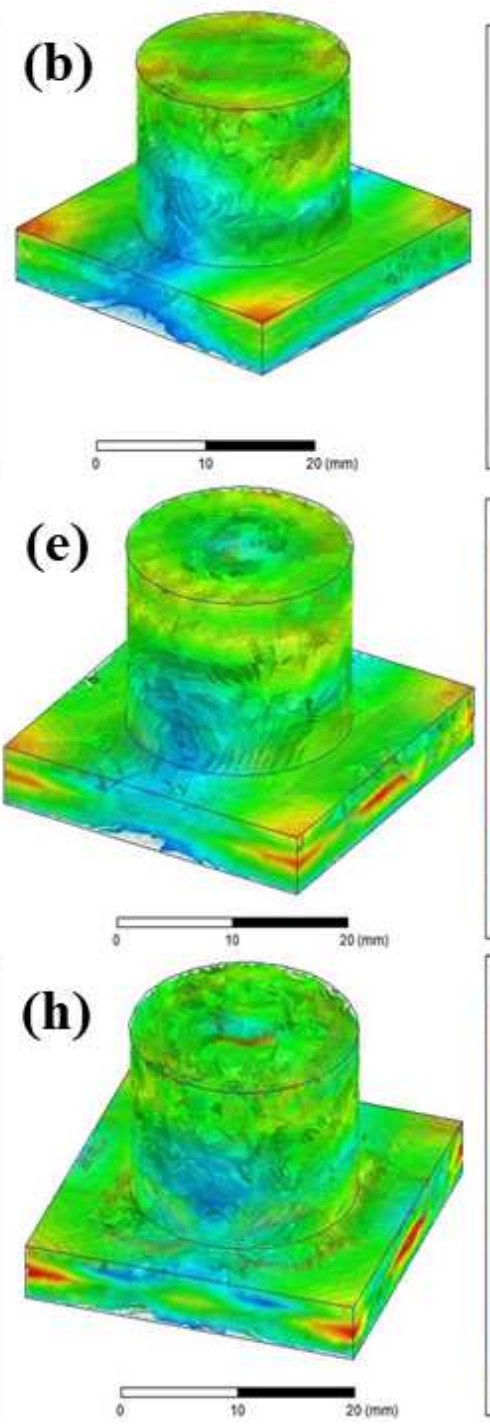
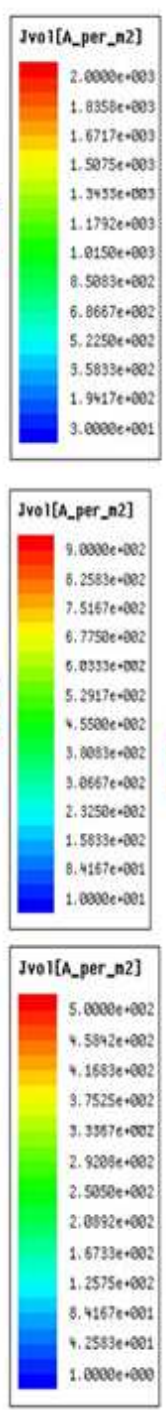
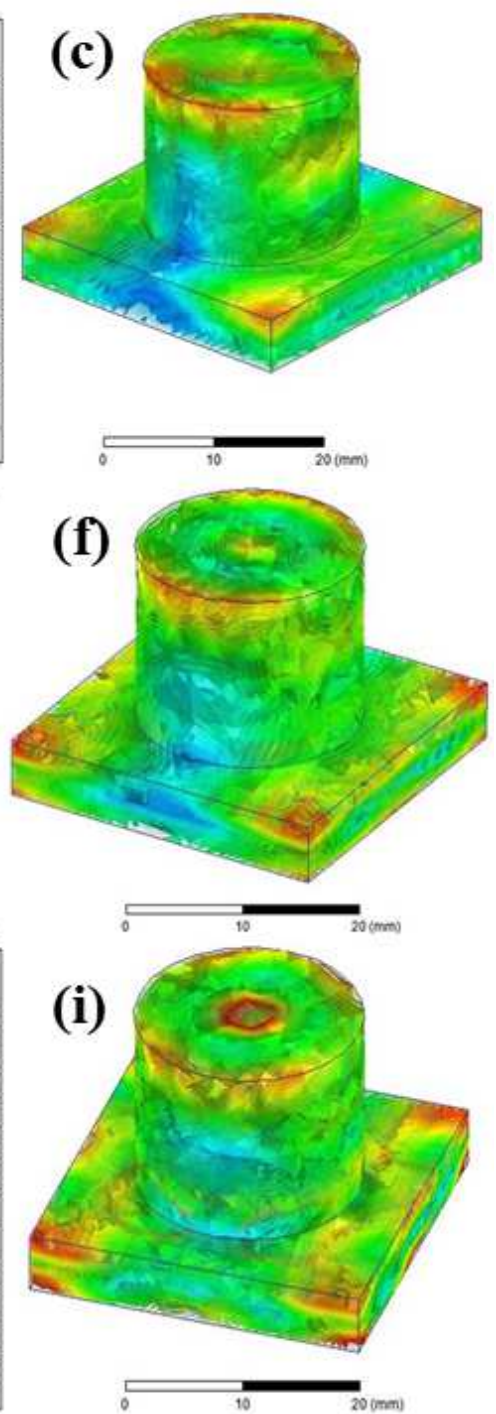

Figure 11

The distribution of electric field (a, d, g), magnetic field (b, e, h), and power loss (c, f, i) of the gypsum composites with 2 wt.\% carbonaceous materials: (a-c) the composites with $2 \mathrm{wt} . \% \mathrm{HCF}$; $(\mathrm{d}-\mathrm{f})$ the composites with 2 wt.\% CNT; (g-i) the composites with 2 wt.\% GE. 


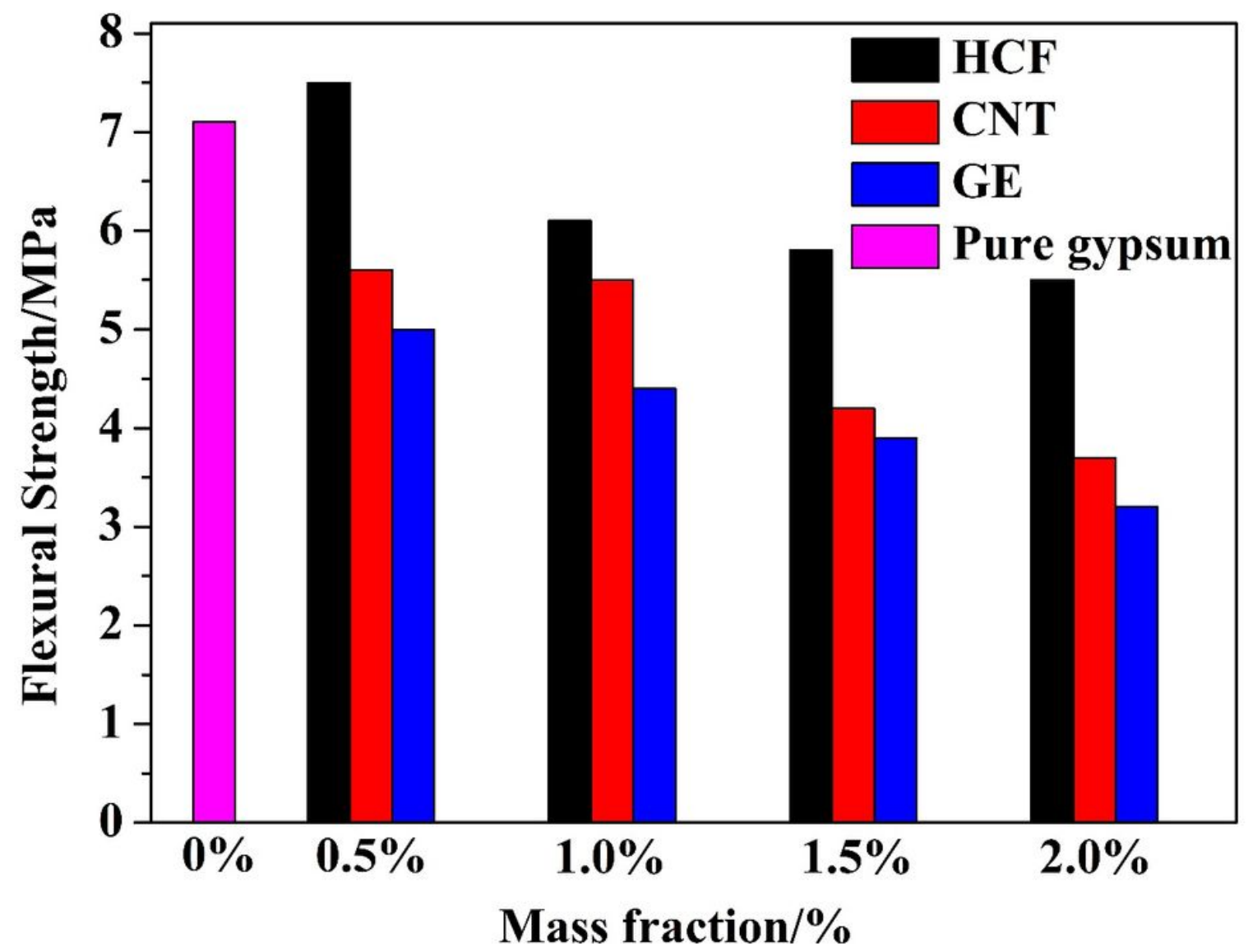

Figure 12

The effects of different carbon materials on the flexural strength of gypsum matrix. 